Illinois State University

ISU ReD: Research and eData

Theses and Dissertations

6-26-2018

\title{
When Does Less Equal More? Assessing The Mechanisms Driving Compensatory Mortality And The Hydra Effect
}

Joseph T. Neale

Illinois State University, jtneale@gmail.com

Follow this and additional works at: https://ir.library.illinoisstate.edu/etd

Part of the Ecology and Evolutionary Biology Commons

\section{Recommended Citation}

Neale, Joseph T., "When Does Less Equal More? Assessing The Mechanisms Driving Compensatory Mortality And The Hydra Effect" (2018). Theses and Dissertations. 919.

https://ir.library.illinoisstate.edu/etd/919

This Thesis is brought to you for free and open access by ISU ReD: Research and eData. It has been accepted for inclusion in Theses and Dissertations by an authorized administrator of ISU ReD: Research and eData. For more information, please contact ISUReD@ilstu.edu. 


\section{WHEN DOES LESS EQUAL MORE? ASSESSING THE MECHANISMS DRIVING COMPENSATORY MORTALITY AND THE HYDRA EFFECT}

\section{JOSEPH T. NEALE}

\section{Pages}

Many populations across taxa are regulated by negative density-dependence, wherein increased population sizes lead to decreased birth rates or increased mortality. By releasing such populations from some level of these density-dependent effects, extrinsic mortality can lead to counter-intuitive results, such as no change in population size (compensation), or an increase in population size (overcompensation). These results have been documented experimentally, but there currently exists a dearth of empirical studies exploring the mechanisms behind the phenomenon. We tested the relationship between extrinsic mortality level and (over)compensation in four mosquito species - Aedes aegypti, A. albopictus, A. triseriatus, and Culex pipiens - by exposing larvae to a range of mortalities by artificial harvest or predation and analyzing the numbers of adults produced. Additionally, we examined the ability of three functionally diverse predators - Mesocyclops longisetus, Anopheles barberi, and Corethrella appendiculata - to induce (over)compensation in A. aegypti by exposing larvae to predation by either single or multiple predator species treatments. We found overcompensation across all levels of mortality in A. triseriatus and C. pipiens and at intermediate levels of mortality in $A$. aegypti. Low-to-intermediate levels of mortality were compensatory in A. albopictus, followed by a decrease in adult production at the highest mortality level. Predation induced compensation in the second experiment and an increase in population equilibrium, a phenomenon known as the 
'hydra effect.' These results provide a better understanding of the conditions under which mortality may increase adult production or population equilibrium. Because overcompensation and the hydra effect are predicted to affect a wide range of taxa and food webs, our findings present implications for developing proper population management and pest reduction strategies. KEYWORDS: hydra effect; compensation; overcompensation; Aedes; Culex pipiens; predatorprey; MPEs; index of performance; density dependence 


\title{
WHEN DOES LESS EQUAL MORE? ASSESSING THE MECHANISMS DRIVING COMPENSATORY MORTALITY AND THE HYDRA EFFECT
}

\author{
JOSEPH T. NEALE
}

\author{
A Thesis Submitted in Partial \\ Fulfillment of the Requirements \\ for the Degree of \\ MASTER OF SCIENCE \\ School of Biological Sciences \\ ILLINOIS STATE UNIVERSITY
}

2018 
(C) 2018 Joseph T. Neale 


\section{WHEN DOES LESS EQUAL MORE? ASSESSING THE MECHANISMS DRIVING COMPENSATORY MORTALITY AND THE HYDRA EFFECT}

JOSEPH T. NEALE

COMMITTEE MEMBERS:

Steven A. Juliano, Chair

Victoria A. Borowicz

Benjamin M. Sadd 


\section{ACKNOWLEDGMENTS}

I am eternally grateful to my friends and family who have provided a lifetime of support and guidance upon which I can always rely. Thank you to the members of the Juliano lab, especially Geoff Ower for training me in mosquito rearing protocols and sharing his problemsolving abilities. This project would not have been possible without the assistance of the undergraduate researchers in the lab, especially Amy Gensler, Keenan Longan, and Kaitlyn Frederick, who dedicated many hours to these experiments. Two fearless women in my lifeRebecca Neale and Whitney Morelli - braved the Florida jungle to assist me during my predator collection trips, for which I cannot thank them enough. Thank you to Vickie Borowicz and Ben Sadd for serving on my thesis committee and offering me their expertise. Finally, I would like to thank my advisor, Steve Juliano, for the enormous amount of guidance and support he has provided throughout my time at ISU. He has instilled in me an even greater appreciation of scientific discovery and the natural world which I will further cultivate in the course of my education and career.

J. T. N. 


\section{CONTENTS}

Page

ACKNOWLEDGMENTS

TABLES

FIGURES

CHAPTER I: FINDING THE SWEET SPOT: WHAT LEVEL OF MORTALITY

LEADS TO POPULATION GROWTH? 1

$\begin{array}{ll}\text { Abstract } & 1\end{array}$

$\begin{array}{ll}\text { Introduction } & 2\end{array}$

$\begin{array}{ll}\text { Methods } & 7\end{array}$

$\begin{array}{ll}\text { Laboratory Colony Rearing } & 7\end{array}$

$\begin{array}{ll}\text { Experimental Setup } & 7\end{array}$

$\begin{array}{ll}\text { Statistical Analyses } & 10\end{array}$

$\begin{array}{ll}\text { Results } & 11\end{array}$

$\begin{array}{ll}\text { Discussion } & 12\end{array}$

Relationship Between Mortality Level And Number Of Survivors 12

Mortality By Predation Versus Artificial Harvest 13

Effects Of Competitive Ability On Overcompensation 14

$\begin{array}{ll}\text { Practical Implications } & 17\end{array}$

$\begin{array}{ll}\text { Literature Cited } & 18\end{array}$

$\begin{array}{ll}\text { Tables } & 24\end{array}$

$\begin{array}{ll}\text { Figure } & 30\end{array}$

CHAPTER II: THE ENEMY OF MY COMPETITOR IS MY FRIEND 32 
$\begin{array}{ll}\text { Abstract } & 32\end{array}$

$\begin{array}{ll}\text { Introduction } & 33\end{array}$

Material and Methods $\quad 36$

$\begin{array}{ll}\text { Organism Collection } & 36\end{array}$

$\begin{array}{ll}\text { Experimental Setup } & 37\end{array}$

Index of Performance $\quad 38$

$\begin{array}{ll}\text { Statistical Analysis } & 39\end{array}$

$\begin{array}{ll}\text { Results } & 40\end{array}$

$\begin{array}{ll}\text { Discussion } & 40\end{array}$

$\begin{array}{ll}\text { References } & 44\end{array}$

$\begin{array}{ll}\text { Table } & 48\end{array}$

$\begin{array}{ll}\text { Figures } & 50\end{array}$ 


\section{TABLES}

Table

Page

1.1 Mixed Effects Generalized Linear Models Testing Survivorship in A. Albopictus

1.2 Parameter Estimates for the Four Models Used to Calculate Model-Averaged Prediction Values for A. Albopictus

1.3 Mixed Effects Generalized Linear Models Testing Survivorship in A. Aegypti

1.4 Mixed Effects Generalized Linear Models Testing Survivorship in C. Pipiens

1.5 Mixed Effects Generalized Linear Models Testing Survivorship in A. Triseriatus

1.6 Parameter Estimates from A. Aegypti, A. Triseriatus, and C. Pipiens Models

2.1 Post Hoc Tests Comparing Treatment Effects on $r^{\prime}$, Female Adult Production, and Female Development Time 


\section{FIGURES}

Figure $\quad$ Page

1.1 Observed and Predicted Numbers of Mosquito Survivors Across a Mortality Range 31

2.1 Mean Numbers of Adult A. Aegypti Produced by Predator Treatment 51

2.2 Mean Indices of Performance $\left(r^{\prime}\right)$ by Predator Treatment 52

2.3 Mean Female Wing Length (a) and Days to Adulthood (b) by Predator Treatment 53 


\title{
CHAPTER I: FINDING THE SWEET SPOT: WHAT LEVEL OF MORTALITY LEADS TO
} POPULATION GROWTH?

\begin{abstract}
Extrinsic mortality applied to negatively density-dependent populations can result in no change in number of survivors (compensation) or an increase in number of survivors (overcompensation) by releasing the survivors from some level of density-dependent effects. Theoretical studies have attempted to elucidate the mechanisms behind this phenomenon, but there is little empirical work testing the predictions of those efforts. The purpose of this study is to examine the relationship between the level of extrinsic mortality (i.e., percentage of mortality) and the level and likelihood of overcompensation. We test the hypotheses that 1) overcompensation is induced at low-to-intermediate levels of extrinsic mortality with additive mortality occurring above a threshold, and 2) different species exhibit varying levels and likelihood of (over)compensation due to differential responses to density. These hypotheses were tested in four container mosquitoes species (Diptera: Culicidae)-Aedes aegypti, A. albopictus, A. triseriatus, and Culex pipiens. Cohorts of 150 larvae were exposed to either artificial harvest ranging from $0-70 \%$ on day 2 or exposure to predation by 1,2 , or 3 Mesocyclops longisetus (Crustacea: Copepoda). The number of adults produced per container was recorded and analyzed by species using mixed-effects generalized linear models. Aedes triseriatus and C. pipiens demonstrated overcompensation across all mortality levels. Overcompensation was induced in A. aegypti up to the $50 \%$ mortality level, followed by compensation at $70 \%$. Mortality was compensatory from $0-50 \%$ in $\mathrm{A}$. albopictus, followed by partial compensation above $50 \%$. Mortality from predation by $M$. longisetus led to greater adult production compared to artificial harvest in A. aegypti and A. albopictus and less adult
\end{abstract}


production in C. pipiens. Our results do not provide full support for our first hypothesis, but rather demonstrate three species-specific patterns in the relationship between extrinsic mortality level and (over)compensation. Our second hypothesis was supported. The relative levels of (over)compensation demonstrated in the four species is inversely related to their competitive abilities and responses to density. These results provide further insight on the mechanisms driving a phenomenon that is predicted to affect many taxa and food webs, and they present practical implications for developing effective strategies to control pest populations.

Keywords: overcompensation; density-dependence; predator-prey; Aedes; Culex pipiens; hydra effect.

\section{Introduction}

Population responses to extrinsic sources of mortality, such as harvesting and predation, have traditionally been predicted to result in a net reduction in population size. Extrinsic mortality, it would be reasoned, interacts additively with intrinsic mortality sources such as intraspecific resource competition. Under certain circumstances, however, extrinsic mortality may produce less intuitive results. Populations regulated by negative density-dependent effects are constrained by intrinsic mortality or reductions in reproduction rates as population sizes approach and exceed the carrying capacity of their habitats (Sibly et al. 2005). Extrinsic mortality affecting such populations can yield the "hydra effect," wherein an increase in population equilibrium density is produced (Abrams and Matsuda 2005). This depends on the production of the same (compensation) or a greater (overcompensation) number of surviving individuals in the following life-stage as would occur without the extrinsic mortality.

Compensation may occur when extrinsic mortality kills individuals that would have otherwise 
died of intrinsic mortality sources. If removal of these individuals leads to greater per capita resource levels for the surviving population, overcompensation may occur.

The hydra effect was first postulated in Ricker (1954), in which fishery-based models yielded population density increases in response to extrinsic mortality applied to immature life stages. Since Ricker's (1954) publication, this phenomenon has been the subject of multiple theoretical studies to determine the conditions under which the hydra effect may occur (reviewed in Abrams 2009). The timing of extrinsic mortality relative to density-dependent events on a population is predicted to be a key factor in determining whether increases in population density will occur (Jonzen and Lundberg 1999, Ratikainen et al. 2008, Abrams 2009, Zipkin et al. 2009, Hilker and Liz 2013, McIntire and Juliano 2018). Mortality occurring before the onset of density-dependence is predicted to lead to overcompensatory responses in population density (Jonzen and Lundberg 1999, Abrams 2009, McIntire and Juliano 2018). Life history traits can further influence the occurrence of overcompensation fluence the occurrence of overcompensation (De Roos et al. 2007, Zipkin et al. 2009, Karatayev and Kraft 2015). Population regulation by maturation versus reproduction determines whether overcompensation can occur in the juvenile and adult stage (De Roos et al. 2007), and high reproduction rates and static maturation rates are postulated to increase the chances of overcompensation in adults (Zipkin et al. 2009, Karatayev and Kraft 2015).

Overcompensatory mortality and the hydra effect are predicted to occur in a wide variety of food web structures (Cortez and Abrams 2016). However, despite the number of theoretical studies examining the hydra effect, there are relatively few empirical examples in natural or laboratory populations. Compensatory mortality has been demonstrated in response to harvest (Weber et al. 2016), predation (Nannini and Juliano 1998), and parasitism (Washburn et al. 
1991), and overcompensation has been demonstrated in response to harvest (Nicholson 1954, Cameron and Benton 2004, Zipkin et al. 2008), parasitism (Washburn et al. 1991), and real or simulated toxin exposure (Agudelo-Silva and Spielman 1984, Moe et al. 2002). While these empirical studies document the occurrence of the phenomenon, the mechanisms underlying the hydra effect remain elusive.

The extent of extrinsic mortality impinging on a population (i.e. the percentage of the population killed) should affect whether compensation or overcompensation occurs (Boyce et al. 1999, Ratikainen et al. 2008, Abrams 2009, Zipkin et al. 2009). There should exist a threshold above which extrinsic mortality is additive to intrinsic mortality sources (Boyce et al. 1999, Ratikainen et al. 2008, Abrams 2009). Above this threshold, extrinsic mortality removes a proportion of the population that exceeds the proportion that would have been removed due to density-dependent effects, thus lowering survivorship and population density. Understanding the relationship between level of mortality and overcompensation would provide a better understanding of the population processes occurring and enable better decisions about managed populations. However, we have only found one empirical study that examines this relationship (Sandercock et al. 2011). Sandercock et al. (2011) found a partially compensatory response to harvest (harvest reduced population size, but at a lower magnitude than the amount harvested) in willow ptarmigan populations at $15 \%$ harvested and an additive response at $30 \%$ harvested. This additive response is predicted to occur when extrinsic mortality exceeds the level of densitydependent mortality (Sandercock et al. 2011). While this study did not demonstrate full compensation nor overcompensation, the results are none-the-less informative about the relationship between level of mortality and compensation, and it provides support for predictions from theory (Boyce et al. 1999, Ratikainen et al. 2008, Abrams 2009, Zipkin et al. 2009). 
The strength of density-dependent effects regulating a population should affect the level of overcompensation induced by extrinsic mortality, as overcompensation occurs when extrinsic mortality releases a population from some level of density-dependent effects. Stronger densitydependent effects result in greater suppression of population sizes at high densities than do weak density-dependent effects. This greater suppression provides the potential for a larger increase in population size due to overcompensation. By this logic, populations facing stronger densitydependence are predicted to have greater levels of overcompensation than similar populations facing weaker density-dependence. However, this predicted relationship between the strength of density-dependent effects and overcompensation has yet to be tested in any published study we have found.

The purpose of this study is to test the effects of multiple levels of extrinsic mortality of larvae on induction of overcompensation of adult production. This question was tested in four container mosquito species (Diptera: Culicidae): Aedes aegypti, A. albopictus, A. triseriatus, and Culex pipiens. These species are suited for studies examining overcompensation because they are highly negative-density dependent in their aquatic larval stages (Dye 1984, Léonard and Juliano 1995, Lord 1998, Alto et al. 2012). To compare responses to artificial and natural mortality sources, we included in our experiment random harvest and predation from Mesocyclops longisetus (Crustacea: Copepoda) as sources of extrinsic mortality. While past empirical studies on overcompensation and the hydra effect have used artificial harvesting or predation as sources of mortality, none to date have compared the two. Differences between the two mortality sources (e.g., selectivity of mortality, the amount of biomass left behind in the form of partially consumed victims, or anti-predator behavior modifications in prey) may result in different likelihoods or levels of overcompensation. 
Based on past theoretical predictions (Boyce et al. 1999, Ratikainen et al. 2008, Abrams 2009, Zipkin et al. 2009) and the work of Sandercock (2011), we hypothesize that overcompensation occurs at low to intermediate levels of extrinsic mortality, with additive mortality occurring above a threshold. If this hypothesis is correct, we predict 1) low-tointermediate levels of extrinsic mortality applied at early larval stages of container mosquitoes will yield an increase in adult production, 2) above a threshold of extrinsic mortality, the number of adults will decrease with added extrinsic mortality, and 3) if mortality imposed by real predators and artificial harvest are equally random with respect to individuals' traits, they will impose similar levels of overcompensation in adult production for similar levels of mortality; alternatively if real predators selectively remove individuals more or less likely to die due to intrinsic mortality, then we expect the two mortality sources to yield different levels of overcompensation. Our second hypothesis is that due to differential competitive abilities and responses to larval density, different species will exhibit varying likelihood and levels of (over)compensatory mortality. Resource competition appears to be strong in larvae of container mosquitoes (reviewed by Juliano 2009, 2010), and general theory (Tilman 1982, Chase and Leibold 2003) and experiments with these mosquito species (Murrell and Juliano 2012) indicate that ability to maintain survival and population growth at low per capita resource levels is the main determinant of competitive ability. Based on the competitive abilities of the four species included in this experiment (Peters et al. 1969, Barrera 1996, Grill and Juliano 1996, Juliano 1998, 2009, 2010, Carrieri et al. 2003, Braks et al. 2004, Costanzo et al. 2005, Reiskind and Lounibos 2009, Murrell and Juliano 2012, O’Neal and Juliano 2013), we predict the respective levels of (over)compensation demonstrated in the four species will be, from highest to lowest, $C$. pipiens, A. triseriatus, A. aegypti, and A. albopictus, as this coincides with their competitive 
abilities.

Methods

Laboratory colony rearing

The mosquitoes used in this study were from laboratory colonies at Illinois State University, Normal, IL, that were initiated with field-collected larvae and pupae from: New Orleans, LA (A. aegypti); Tyson Research Center in Eureka, MO (A. triseriatus); Harrisburg, PA (A. albopictus); and Normal, IL (C. pipiens). The colonies had been maintained in the lab for approximately 3 years (A. aegypti), 2.5 years (A. albopictus), and 1 year (A. triseriatus and $C$. pipiens) Adults were provided blood meals from anesthetized guinea pigs and mice (IUCAC\# 842043). Eggs from the three Aedes species were deposited on seed germination paper and allowed to embryonate for at least two weeks. Culex pipiens eggs were deposited in a timothy hay/oak leaf infusion.

Mesocyclops longisetus occurs in South and Central America as well as parts of the southern United States (Reid 1993). They are voracious predators of mosquito larvae, and individuals are capable of killing up to 38 larvae per day (Marten et al. 1994). M. longisetus used in this study were taken from a laboratory colony maintained at Illinois State University in Normal, IL, which originated from a colony maintained at the Florida Medical Entomology Laboratory (FMEL) in Vero Beach, FL. The colony was housed at room temperature in 2-quart plastic storage containers and provided Paramecia caudata approximately bi-monthly as food resources.

Experimental setup

Four days prior to the beginning of the experiment, $500 \mathrm{ml}$ plastic containers were filled with $400 \mathrm{ml}$ ultrapure water, $1 \mathrm{~g}$ dried live oak leaves (Quercus viriginiana) collected from Vero 
Beach, FL, $0.05 \mathrm{~g}$ dried decorated crickets (Gryllodes sigillatus), and $100 \mu 1$ microbial inoculum collected from a rain-filled bucket in Merwin Nature Preserve, Lexington, IL. Lids were placed on the containers with holes punched for ventilation. Containers were housed in an environmental chamber at $25^{\circ} \mathrm{C}$ until the beginning of the experiment to allow the establishment of a microbial community to serve as food resources for mosquito larvae.

Eggs from the three Aedes species were hatched by placing strips of egg papers in vials containing $0.4 \mathrm{~g} / 1$ Difco ${ }^{\mathrm{TM}}$ nutrient broth (Becton, Dickinson and Company, Sparks, MD) mixed with ultrapure water and stored for 24 hours at $25^{\circ} \mathrm{C}$. Culex pipiens eggs were collected on the day as oviposition and stored in ultrapure water at $25^{\circ} \mathrm{C}$ for 24 hours. At the start of the experiment, hatchling larvae of all species were rinsed in ultrapure water prior to counting.

Containers $(n=204)$ were randomly assigned a species and mortality treatment. Mortality treatments consisted of either a percentage of the cohort $(0,10,30,50$, or $70 \%)$ to be removed at random on day 2 , or the addition of 1, 2, or 3 female M. longisetus as predator treatments. On day 0 of the experiment, 150 mosquito hatchlings of one species were added to appropriate containers, and $M$. longisetus were added to predator treatment containers. This initial density of mosquito larvae was chosen because Containers were returned to the environmental chamber, which maintained a 14:10 light:dark photoperiod.

Artificial mortality treatments were applied on day 2, as this timing has been demonstrated to be most likely to induce overcompensation in this system (McIntire and Juliano 2018). Each container was emptied into an enamel pan and leaves were removed and set aside. Surviving larvae in predator containers were counted and returned to the containers with the leaves, and the percent mortality by day 2 due to predation was determined as the proportion of the initial 150 larvae that were missing or dead. Predators were difficult to detect with certainty 
in these containers, so they were not removed. Artificial mortality treatments were applied by randomly removing surviving larvae until the number of remaining individuals equaled the appropriate percentage of the original cohort size (150). After stirring the water with larvae in the pan, an array of $6 \mathrm{PVC}$ pipes $4 \mathrm{~cm}$ long and $2.5 \mathrm{~cm}$ in diameter were placed in the water, trapping larvae within the pipes. A random number generator was used to select one of the numbered pipes, and larvae were removed from that section. This process was repeated three times before removing the pipes, stirring the contents, and replacing the pipes. This process was repeated until the desired number of survivors remained in each container. Larvae removed were set aside for each species and added, as needed, to any artificial mortality container with fewer survivors than needed for its assigned mortality treatment. The average number of survivors by day 2 in artificial mortality treatments was 138, and all $0 \%$ mortality containers required an addition of mosquitoes to reach 150 . Thus, at 2 days, we precisely controlled the numbers of larvae surviving in artificial mortality containers.

On days 16 and 30, 0.5g dried live oak (Quercus virginiana) leaves and $0.025 \mathrm{~g}$ dried decorated crickets were added to each Aedes container, and on days 9, 16, 23, and 30, the same amounts were added to the $C$. pipiens containers. More frequent resource additions were used for C. pipiens because initial trials using the same feeding schedule as the Aedes containers failed to produce adults in all C. pipiens treatments. Containers were checked daily for pupae, which were removed and placed in 0.25 dram vials with cotton stoppers. Pupae were stored in the environmental chamber and checked daily for emergence, and the date of emergence for each individual was recorded. All individuals reaching adulthood were counted as survivors. 


\section{Statistical analyses}

This experiment was conducted in incomplete time blocks $(\mathrm{n}=8)$ over a period of 9 months. Blocks were incomplete due to egg availability. A single quantitative mortality variable was created to enable comparison of artificial mortality and predator-induced mortality. This mortality variable was equal to the percent of individuals removed on day 2 for artificial mortality treatments and the percentage of mortality due to predation observed on day 2 for predator treatments. Because Aedes and Culex species were given different food treatments, they were analyzed separately. The number of survivors per container was analyzed using a mixedeffects generalized linear model with PROC GLIMMIX in SAS 9.4. Models including predator presence/absence, species (Aedes analysis only), mortality, mortality ${ }^{2}$, mortality $^{3}$, and all interactions, with block included as a random effect, were evaluated. Higher-order polynomial terms were not tested in models without lower order terms. To correct for over-dispersion, a negative binomial error distribution was used. Because the species*mortality interaction was significant in the Aedes analysis (see Results), separate regressions were run to select the best model for each species. Corrected Akaike's information criteria (AICc; Sugiura 1978) were compared to determine the best model, and the model with the lowest evidence ratio was selected in the case of A. aegypti, A. triseriatus, and C. pipiens. The two A. albopictus models with the lowest AICcs were similar in value (Table 1.1), so excluding the second-best model would discard valuable information. The most likely model contained the predator effect alone, while the second-most likely model contained predator and a cubic relationship to mortality. Since the third and fourth best models contained the linear and quadratic relationships to mortality, respectively, and the evidence ratio for the fourth model was relatively low $(\mathrm{E}=2.044)$, these four models were averaged following methods described in Anderson (2008) to calculate predicted 
numbers of survivors and standard errors, which were weighted by their respective model weight $\left(\mathrm{w}_{\mathrm{i}}\right)$ values when all unselected models were excluded (Table 1.2). These four models had a combined weight of $\mathrm{w}_{\mathrm{i}}=0.7037$ when all possible models were considered (Table 1.1 , sum of $\mathrm{w}_{\mathrm{i}}$ from top 4 models).

\section{Results}

The mortality*species interaction was significant in the analysis combining all three Aedes species $\left(\mathrm{F}_{2,132}=15.55, \mathrm{p}<0.0001\right)$. Therefore, we report here the results from the singlespecies analyses. The model average prediction for $A$. albopictus incorporated predictions from the predator-only $\left(\mathrm{w}_{\mathrm{i}}=0.3376\right)$, predator + a cubic relationship to mortality $\left(\mathrm{w}_{\mathrm{i}}=0.3054\right)$, predator + linear effect of mortality $\left(\mathrm{w}_{\mathrm{i}}=0.1919\right)$, and predator + a quadratic relationship to mortality $\left(\mathrm{W}_{\mathrm{i}}=0.1651\right)$ models (Table 1.1). This model-averaged prediction showed no change in number of survivors with added mortality (compensation) through the $50 \%$ mortality level, followed by a decrease in survivorship (Table 1.1, Figure 1.1). Mortality by predation resulted in greater number of survivors than did artificial mortality, with predator treatments yielding 3.74-7.19 more survivors depending on the model (Table 1.2).

The $A$. aegypti and $C$. pipiens data were each best characterized by the models containing predator and a cubic relationship to mortality (Tables 3 and 4), while the A. triseriatus data were best fit by a model containing only the linear effect of mortality (Table 1.5). The effect of predator was significantly positive for $A$. aegypti with an estimate of 5.80 more adults produced in predator treatments and negative for $C$. pipiens with an effect of 1.88 fewer adults produced in predator treatments (Table 1.6, Figure 1.1). Aedes aegypti showed a slight decrease in survivors with low mortality levels compared to the $0 \%$ mortality level, but this trend reversed between $10 \%$ and $30 \%$ mortality, resulting in compensation at 30\% (Table 1.6, Figure 1.1). Intermediate 
levels of mortality were overcompensatory, with more adults produced compared to $0 \%$ mortality level, and the number of survivors dropped to approximately equal numbers compared to no mortality by the $70 \%$ level (Table 1.6, Figure 1.1). Aedes triseriatus demonstrated overcompensation across the entire range of mortality applied, with a linear increase in survivors as greater levels of mortality were applied (Table 1.6, Figure 1.1). Culex pipiens showed an overcompensatory response at all mortality levels, with the greatest number of survivors produced in the $30 \%$ mortality level (Table 1.6, Figure 1.1). Survivors dropped in the higher mortality levels compared to $30 \%$, but the number remained greater than that at the $0 \%$ level.

\section{Discussion}

Relationship between mortality level and number of survivors

Overcompensation was observed in the production of A. aegypti, A. triseriatus, and $C$. pipiens adults at some (A. aegypti) or all (A. triseriatus and C. pipiens) ranges of extrinsic mortality imposed, whereas A. albopictus cohorts demonstrated compensatory, followed by partial compensation. Our first prediction of our first hypothesis - that overcompensation would occur at low-to-intermediate levels of extrinsic mortality - was supported in A. aegypti, A. triseriatus, and C. pipiens, but not A. albopictus. The partial compensation at the $70 \%$ extrinsic mortality level in A. albopictus trended towards supporting our second prediction, but we did not see support for this prediction in the other three species. Mortality imposed by both predation and artificial harvest induced overcompensation in A. aegypti, A. triseriatus, and, C. pipiens, supporting our third prediction, but not in A. albopictus. Because all three predictions were not confirmed for any single species, we did not find full support for our first hypothesis. Our results demonstrated three patterns in responses to mortality: 1) overcompensation induced at all levels of extrinsic mortality (seen in A. triseriatus and C. pipiens data), 2) overcompensation 
induced at low-to-intermediate levels of extrinsic mortality followed by compensation above a threshold mortality level (seen in A. aegypti data), and 3) compensation induced at low-tointermediate levels of extrinsic mortality followed by partial compensation above a threshold (seen in A. albopictus data). The variation in patterns between species is likely a result of differences in responses to density (see 'effects of competitive ability on overcompensation' section).

Mortality by predation versus artificial harvest

Mortality by predation led to greater adult production than did artificial mortality in $A$. aegypti and A. albopictus. Artificial mortality in this experiment was imposed by randomly removing individuals from the containers, resulting in the complete loss of biomass from the harvested individuals. However, predation by M. longisetus releases feces and unconsumed body parts to the system, potentially enhancing resources for the microbial communities on which mosquitoes feed, which may explain the greater numbers of adults produced in predator treatments. Furthermore, the selectivity of the artificial and predator-induecd mortalities likely influenced the difference in adult production as well. Individuals were selected at random for removal in artificial mortality treatments, while lower-quality individuals (e.g., smaller, slower, less robust) were likely to be consumed in the predator treatments. If this selective removal of less robust larvae occurred with real predation, it may have resulted in higher-quality survivors than did the random removal treatments, with correspondingly greater likelihood of survival to adulthood.

In contrast to $A$. aegypti and A. albopictus, fewer $C$. pipiens adults were produced when exposed to predation than to artificial mortality. Culex pipiens has a longer larval development period than the three Aedes species used in this experiment. Since M. longisetus is a size- 
selective predator, primarily feeding on $1^{\text {st }}$ and $2^{\text {nd }}$ instar larvae (Marten and Reid 2007), this longer development time would result in an increased duration of vulnerability to predation. Most larvae in Aedes treatments appeared to have grown sufficiently to have low risk of predation by day 2 , when survivors were counted, and the percent mortality induced by predation was calculated. If fewer $C$. pipiens larvae reached this refuge by day 2 , predation may have continued after the census of survivors. If predation continued beyond the point at which density-dependence became important, it would likely interact additively with intrinsic mortality (Abrams 2009, McIntire and Juliano 2018). This additive mortality may have counteracted overcompensation in predator containers, thus leading to a lower number of survivors induced by predation compared to artificial mortality.

\section{Effects of competitive ability on overcompensation}

Our second hypothesis - different species exhibit varying likelihoods of (over)compensatory mortality due to differential competitive abilities and responses to harvest was supported. The extent of overcompensation differed among the three Aedes species in a pattern consistent with past studies examining their relative competitive abilities and responses to density. Under natural settings and in microcosms simulating natural settings, A. albopictus is the superior competitor of the three, followed by $A$. aegypti, and A. triseriatus is the weakest competitor (Barrera 1996, Grill and Juliano 1996, Juliano 1998, 2009, 2010, Braks et al. 2004, Reiskind and Lounibos 2009, Murrell and Juliano 2012, O’Neal and Juliano 2013), and competitive abilities are determined by the a species' ability to persist at low per capita resource levels (Tilman 1982, Chase and Leibold 2003, Murrell and Juliano 2012). Because overcompensation occurs when extrinsic mortality releases a surviving population from some level of density-dependent effects, stronger density-dependent regulation of the population 
should be associated with greater levels of overcompensation, or a greater range of conditions leading to overcompensation. Culex pipiens is the weakest competitor of the four species (Peters et al. 1969, Carrieri et al. 2003, Costanzo et al. 2005); however, because of the different food regimes used for the C. pipiens and Aedes experiments, we are not confident of comparability of the responses of the two genera.

The patterns observed in the responses to mortality between the four species suggest competitive ability and associated strengths of density-dependent effects regulating a population may influence which of the three alternative hypotheses previously described occurs in response to extrinsic mortality. This would indicate the likelihood of (over)compensation differs not only between species, but also with variation in per capita resource levels among conspecific populations. Thus, raising the strength of density-dependent effects in this experiment by reducing resource levels or increasing cohort sizes may be expected to lead to greater levels of overcompensation. Whereas A. albopictus did not show overcompensation in this experiment, we predict decreasing the per capita resource level would increase the likelihood of overcompensation in response to mortality. McIntire and Juliano (2018) conducted an experiment with A. albopictus with the same resource levels and nearly the same level of random mortality on day 2 using a cohort size of 250 larvae. They found strong overcompensation in $A$. albopictus at $48 \%$ mortality, which is consistent with our expectation that per capita resource levels and population density are strong determinants of likelihood and strength of overcompensation, at least for $A$. albopictus. Further experimentation is necessary to understand the general relationship between strength of density-dependent effects and (over)compensation.

The shift to partial above a threshold in A. albopictus is consistent with the findings in Sandercock et al. (2011) and Pardini et al. (2009), as well as past theoretical models (Boyce et al. 
1999, Ratikainen et al. 2008, Abrams 2009, Zipkin et al. 2009). The absence of this result in our A. aegypti, A. triseriatus, and C. pipiens data suggests the range of extrinsic mortality included in this study was not sufficiently high to induce additive mortality. The level of mortality that serves as the threshold for additive mortality is predicted to be determined by the proportion of mortality due to density-dependent effects in the absence of extrinsic mortality (Sandercock et al. 2011). Populations exhibiting higher density-dependent mortality levels in the absence of extrinsic mortality would demonstrate a higher threshold for extrinsic mortality to become additive (Sandercock et al. 2011). Our findings support this prediction, as only the species believed to be the best competitor and postulated to have the lowest level of density-dependent mortality (A. albopictus) demonstrated a threshold to additive mortality within the range of extrinsic mortalities included in our study. According to the level of density-dependent mortality that occurred at the $0 \%$ mortality level, A. albopictus would be predicted to exhibit a threshold to additivity at approximately $59 \%$, which is close to the $50 \%$ threshold demonstrated here. Mortality would be predicted to become additive in A. aegypti at the $62 \%$ mortality level, which we did not see. However, the drop to compensation at the $70 \%$ mortality level suggests the additive threshold was not much higher. Aedes triseriatus and C. pipiens would be predicted to exhibit thresholds to additive mortality at $88 \%$ and $97 \%$, respectively, which exceed the mortality range tested in this study. Decreasing the density-dependent mortality of the other three species by increasing the per-capita resource levels may lower the threshold for additive mortality to exist within the $0-70 \%$ mortality range used here, but further experimentation is needed to explore this possibility. 


\section{Practical implications}

Determining the mechanisms by which overcompensation and the hydra effect can occur is critical for effectively managing pest populations. Interventions aimed at control of densitydependent populations can lead to counter-productive results (Agudelo-Silva and Spielman 1984, Buckley et al. 2001, Pardini et al. 2009). The four mosquito species used in this study are important vectors of mosquito borne viruses (Eldridge et al. 2000) and are targets of control efforts within their ranges. The results of this study demonstrate the potential importance of using pest-control strategies that minimize the risk of imposing mortality levels that can be offset by a release from density-dependence. To avoid inducing (over)compensation, control strategies must result in sufficiently high levels of mortality to surpass the threshold for additive mortality demonstrated by the target population. Mesocyclops longisetus has been successfully used as a biocontrol agent of several mosquito species, including the three Aedes species tested in this study (Marten et al. 1994, Soumare and Cilek 2011). Our results suggest the success of $M$. longisetus at reducing mosquito population sizes is not only dependent on its predation rate but is also likely to depend on its numerical response. Inoculations of $M$. longisetus to mosquito habitats must include large numbers of copepods and provide a suitable environment for maintenance of a large copepod population to avoid overcompensation in mosquito adult production. 


\section{Literature Cited}

Abrams, P. A. 2009. When does greater mortality increase population size? The long history and diverse mechanisms underlying the hydra effect. Ecology Letters 12:462-474.

Abrams, P. A., and H. Matsuda. 2005. The effect of adaptive change in the prey on the dynamics of an exploited predator population. Canadian Journal of Fisheries and Aquatic Sciences $62: 758-766$.

Agudelo-Silva, F., and A. Spielman. 1984. Paradoxical effects of simulated larviciding on production of adult mosquitoes. American Journal of Tropical Medicine and Hygiene 33:1267-1269.

Alto, B. W., E. J. Muturi, and R. L. Lampman. 2012. Effects of nutrition and density in Culex pipiens. Medical and Veterinary Entomology 26:396-406.

Anderson, D. R. 2008. Multimodel inference. Pages 105-124 Model Based Inference in the Life Sciences: A Primer on Evidence. Springer, Fort Collins, CO.

Barrera, R. 1996. Competition and resistance to starvation in larvae of container-inhabiting Aedes mosquitoes. Ecological Entomology 21:117-127.

Boyce, M. S., A. R. E. Sinclair, and G. C. White. 1999. Seasonal compensation of predation and harvesting. Oikos 87:419.

Braks, M. A. H., N. A. Honório, L. P. Lounibos, R. Lourenço-De-Oliveira, and S. A. Juliano. 2004. Interspecific competition between two invasive species of container mosquitoes, Aedes aegypti and Aedes albopictus (Diptera: Culicidae), in Brazil. Annals of the Entomological Society of America 97:130-139. 
Buckley, Y. M., H. Hinz, D. Matthies, and M. Rees. 2001. Interactions between densitydependent processes, population dynamics and control of an invasive plant species, Tripleurospermum perforatum (scentless chamomile). Ecology Letters 4:551-558.

Cameron, T. C., and T. G. Benton. 2004. Stage-structured harvesting and its effects: an empirical investigation using soil mites. Journal of Animal Ecology 73:996-1006.

Carrieri, M., M. Bacchi, R. Bellini, and S. Maini. 2003. On the Competition Occurring Between Aedes albopictus and Culex pipiens (Diptera: Culicidae) in Italy. Environmental Entomology 32:1313-1321.

Chase, J., and M. Leibold. 2003. Ecological niches: linking classical and contemporary approaches. University of Chicago Press, Chicago.

Cortez, M. H., and P. A. Abrams. 2016. Hydra effects in stable communities and their implications for system dynamics. Ecology 97:1135-1145.

Costanzo, K. S., K. Mormann, and S. A. Juliano. 2005. Asymmetrical competition and patterns of abundance of Aedes albopictus and Culex pipiens. Journal of Medical Entomology 42:559-570.

Dye, C. 1984. Models for the population dynamics of the yellow fever mosquito, Aedes aegypti. Journal of Animal Ecology 53:247-268.

Eldridge, B. F., T. W. Scott, J. F. Day, and W. J. Tabachnick. 2000. Arbovirus diseases. Pages 415-460 in B. F. Eldridge and J. D. Edman, editors. Medical Entomology: A textbook on Public Health and Veterinary problems caused by arthropods. Kluwer Academic Publishers, Dordrecht, The Netherlands. 
Grill, C. P., and S. A. Juliano. 1996. Predicting species interactions based on behaviour: predation and competition in container-dwelling mosquitoes. Journal of Animal Ecology 65:63-76.

Hilker, F. M., and E. Liz. 2013. Harvesting, census timing and "hidden" hydra effects. Ecological Complexity 14:95-107.

Jonzen, N., and P. Lundberg. 1999. Temporally structured density-dependence and population management. Annales Zoologici Fennici 36:39-44.

Juliano, S. A. 1998. Species introduction and replacement among mosquitoes: interspecific resource competition or apparent competition? Ecology 79:255-268.

Juliano, S. A. 2009. Species interactions among larval mosquitoes: context dependence across habitat gradients. Annual review of entomology 54:37-56.

Juliano, S. A. 2010. Coexistence, exclusion, or neutrality? A meta-analysis of competition between Aedes albopictus and resident mosquitoes. Isr J Ecol Evol 56:325-351.

Karatayev, V. A., and C. E. Kraft. 2015. Racing through life: maturation rate plasticity regulates overcompensation and increases persistence. Ecosphere 6:1-12.

Léonard, P. M., and S. A. Juliano. 1995. Effect of leaf litter and density on fitness and population performance of the hole mosquito Aedes triseriatus. Ecological Entomology 20:125-136.

Lord, C. C. 1998. Density dependence in larval Aedes albopictus (Diptera: Culicidae). J Med Entomol 35:825-829.

Marten, G. G., E. S. Bordes, and M. Nguyen. 1994. Use of cyclopoid copepods for mosquito control. Hydrobiologia 292-293:491-496.

Marten, G. G., and J. W. Reid. 2007. Cyclopoid copepods. Journal of the American Mosquito Control Association 23:65-92. 
McIntire, K. M., and S. A. Juliano. 2018. How can mortality increase population size? A test of two mechanistic hypotheses. Ecology.

Moe, S. J., N. C. Stenseth, and R. H. Smith. 2002. Density-dependent compensation in blowfly populations give indirectly positive effects of a toxicant. Ecology 83:1597-1603.

Murrell, E. G., and S. A. Juliano. 2012. Competitive abilities in experimental microcosms are accurately predicted by a demographic index for R*. PLoS ONE 7:1-9.

Nannini, M., and S. A. Juliano. 1998. Effects of the facultative predator Anopheles barberi on population performance of its prey Aedes triseriatus (Diptera: Culicidae). Annals of the Entomological Society of America 1:33-42.

Nicholson, A. J. 1954. An outline of the dynamics of animal populations. Australian Journal of Zoology 2:9-65.

O’Neal, P. A., and S. A. Juliano. 2013. Seasonal variation in competition and coexistence of Aedes mosquitoes: stabilizing effects of egg mortality or equalizing effects of resources? Journal of Animal Ecology 82:256-265.

Pardini, E. A., J. M. Drake, J. M. Chase, T. M. Knight, E. A. Pardini, J. M. Drake, J. M. Chase, and T. M. Knight. 2009. Complex population dynamics and control of the invasive biennial Alliaria petiolata (garlic mustard). Ecological Applications 19:387-397.

Peters, M. T., B. I. Chevone, and R. A. Callahan. 1969. Interactions between larvae of Aedes aegypti (L.) and Culex pipiens L. in mixed experimental populations. Mosquito News 29:435-438.

Ratikainen, I. I., J. A. Gill, T. G. Gunnarsson, W. J. Sutherland, and H. Kokko. 2008. When density dependence is not instantaneous: Theoretical developments and management implications. Ecology Letters 11:184-198. 
Reid, J. W. 1993. New records and redescriptions of American species of Mesocyclops and of Diacyclops bernardi (Petkovski, 1986) (Copepoda: Cyclopoida). Bijdragen tot de Dierkunde 63:173-191.

Reiskind, M. H., and L. P. Lounibos. 2009. Effects of intraspecific larval competition on adult longevity in the mosquitoes Aedes aegypti and Aedes albopictus. Medical and Veterinary Entomology 23:62-68.

Ricker, W. E. 1954. Stock and recruitment. Journal of the Fisheries Research Board of Canada $11: 559-623$.

De Roos, A. M. De, T. Schellekens, T. van Kooten, K. van de Wolfshaar, D. Claessen, and L. Persson. 2007. Food-dependent growth leads to overcompensation in stage-specific biomass when mortality increases: the influence of maturation versus reproduction regulation. The American Naturalist 170:E59-E76.

Sandercock, B. K., E. B. Nilsen, H. Brøseth, and H. C. Pedersen. 2011. Is hunting mortality additive or compensatory to natural mortality? Effects of experimental harvest on the survival and cause-specific mortality of willow ptarmigan. Journal of Animal Ecology 80:244-258.

Sibly, R. M., D. Barker, M. C. Denham, J. Hone, and M. Pagel. 2005. On the regulation of populations of mammals, birds, fish, and insects. Science 309:607-610.

Soumare, M. K. F., and J. E. Cilek. 2011. The effectiveness of Mesocyclops longisetus (Copepoda) for the control of container-inhabiting mosquitoes in residential environments. Journal of the American Mosquito Control Association 27:376-383.

Sugiura, N. 1978. Further analysts of the data by Akaike's information criterion and the finite corrections. Communications in Statistics - Theory and Methods 7:13-26. 
Tilman, D. 1982. Resource competition and community structure. Princeton University Press, Princeton NJ, USA.

Washburn, J. O., D. R. Mercer, and J. R. Anderson. 1991. Regulatory role of parasites: impact on host population shifts with resource availability. Science 253:185-188.

Weber, M. J., M. J. Hennen, M. L. Brown, D. O. Lucchesi, and T. R. St. Sauver. 2016. Compensatory response of invasive common carp Cyprinus carpio to harvest. Fisheries Research 179:168-178.

Zipkin, E. F., C. E. Kraft, E. G. Cooch, and P. J. Sullivan. 2009. When can efforts to control nuisance and invasive species backfire? Ecological Applications 19:1585-1595.

Zipkin, E. F., P. J. Sullivan, E. G. Cooch, C. E. Kraft, B. J. Shuter, and B. C. Weidel. 2008. Overcompensatory response of a smallmouth bass (Micropterus dolomieu) population to harvest: release from competition? Canadian Journal of Fisheries and Aquatic Sciences 65:2279-2292. 


\section{Tables}

Table 1.1 Mixed effects generalized linear models testing survivorship in A. albopictus. Early-instar larvae were exposed to a range of mortality from harvest or predation (pred).

\begin{tabular}{|c|c|c|c|c|c|c|c|}
\hline Model Effects & $\mathrm{AICc}$ & $\Delta \mathrm{AICc}$ & $\exp (-.5 * \Delta \mathrm{AICc})$ & $\mathrm{W}_{\mathrm{i}}^{\mathrm{a}}$ & $E^{a}$ & $\mathrm{w}_{\mathrm{i}}^{\mathrm{b}}$ & $E^{b}$ \\
\hline Pred & 308.91 & 0.00 & 1.00 & 0.24 & 1.00 & 0.34 & 1.00 \\
\hline Pred mortality mortality ${ }^{2}$ mortality ${ }^{3}$ & 309.11 & 0.20 & 0.90 & 0.21 & 1.11 & 0.31 & 1.11 \\
\hline Pred mortality & 310.04 & 1.13 & 0.57 & 0.14 & 1.76 & 0.19 & 1.76 \\
\hline Pred mortality mortality ${ }^{2}$ & 310.34 & 1.43 & 0.49 & 0.12 & 2.04 & 0.17 & 2.04 \\
\hline None & 310.69 & 1.78 & 0.41 & 0.10 & 2.44 & & \\
\hline Mortality & 311.33 & 2.42 & 0.30 & 0.07 & 3.35 & & \\
\hline Pred mortality mortality ${ }^{2}$ mortality ${ }^{3}$ mortality*pred & 312.17 & 3.26 & 0.20 & 0.05 & 5.10 & & \\
\hline Pred mortality mortality*pred & 312.41 & 3.50 & 0.17 & 0.04 & 5.75 & & \\
\hline Pred mortality mortality ${ }^{2}$ pred*mortality & 313.23 & 4.32 & 0.12 & 0.03 & 8.67 & & \\
\hline $\begin{array}{l}\text { Pred mortality mortality }{ }^{2} \text { mortality }{ }^{3} \text { mortality*pred } \\
\text { mortality }{ }^{2 *} \text { pred }\end{array}$ & 315.53 & 6.62 & 0.04 & 0.01 & 27.39 & & \\
\hline $\begin{array}{l}\text { Pred mortality mortality }{ }^{2} \text { mortality }{ }^{3} \text { mortality* pred } \\
\text { mortality }{ }^{2 *} \text { pred mortality }{ }^{3 *} \text { pred }\end{array}$ & 317.10 & 8.19 & 0.02 & 0.00 & 60.04 & & \\
\hline Sum & - & - & 4.21 & - & - & & \\
\hline
\end{tabular}

Note: Weight of evidence $\left(\mathrm{w}_{\mathrm{i}}\right)$ is calculated as $\exp \left(-0.5^{*} \mathrm{AICc}\right) / \sum \exp \left(-0.5^{*} \Delta \mathrm{AICc}\right)$ and estimates the probability the model is correct. The evidence ratio $(\mathrm{E})$ is calculated as $\mathrm{w}_{(\max )} / \mathrm{w}_{\mathrm{i}}$ and expresses how much more likely the best model is than the given one. Higher values indicate a less likely model.

a indicates $\mathrm{w}_{\mathrm{i}}$ and $\mathrm{E}$ values when all models are included in calculations.

${ }^{b}$ indicates $\mathrm{w}_{\mathrm{i}}$ and $\mathrm{E}$ values when only the 4 models incorporated in the model average prediction are included in calculations. 
Table 1.2 Parameter estimates for the four models used to calculate model-averaged prediction values for A. albopictus.

\begin{tabular}{lcccccccccc}
\hline Model Effects & Intercept & $\mathrm{p}>0$ & Pred & $\mathrm{p}>0$ & Mortality & $\mathrm{p}>0$ & Mortality & $\mathrm{p}>0$ & $\begin{array}{c}\text { Mortality } \\
3\end{array}$ & $\mathrm{p}>0$ \\
\hline Pred & 39.53 & $\mathbf{0 . 0 0}$ & 7.19 & $\mathbf{0 . 0 4}$ & - & - & - & - & - & - \\
Pred mort & 42.19 & $\mathbf{0 . 0 0}$ & 7.14 & 0.05 & 0.00 & 0.22 & - & - & - & - \\
Pred mort mort & & 39.50 & $\mathbf{0 . 0 0}$ & 3.74 & 0.29 & 0.01 & 0.25 & 0.00 & 0.12 & - \\
Pred mort mort $^{2}$ mort $^{3}$ & 43.34 & $\mathbf{0 . 0 0}$ & 6.26 & 0.11 & -0.02 & 0.16 & 0.00 & 0.08 & 0.00 & $\mathbf{0 . 0 4}$ \\
\hline
\end{tabular}

Note: Values were produced in a mixed-effects generalized linear model testing the effects of predator (pred) and mortality up to the cubic term on survivorship. 
Table 1.3 Mixed effects generalized linear models testing survivorship in A. aegypti. Early-instar larvae were exposed to a range of mortality from harvest or predation (pred).

\begin{tabular}{|c|c|c|c|c|c|}
\hline Model Effects & $\mathrm{AICc}$ & $\triangle \mathrm{AICc}$ & $\exp \left(-.5^{*} \Delta \mathrm{AICc}\right)$ & $\mathrm{W}_{\mathrm{i}}$ & $\mathrm{E}$ \\
\hline Pred mortality mortality ${ }^{2}$ mortality $^{3}$ & 377.39 & 0.00 & 1.00 & 0.42 & 1.00 \\
\hline Pred mortality & 378.90 & 1.51 & 0.47 & 0.20 & 2.13 \\
\hline Pred mortality mortality*pred & 379.98 & 2.59 & 0.27 & 0.12 & 3.65 \\
\hline Pred mortality mortality ${ }^{2}$ mortality ${ }^{3}$ mortality* pred & 380.07 & 2.68 & 0.26 & 0.11 & 3.82 \\
\hline Pred mortality mortality ${ }^{2}$ & 381.46 & 4.07 & 0.13 & 0.05 & 7.65 \\
\hline Pred mortality mortality ${ }^{2}$ mortality ${ }^{3}$ mortality* pred mortality ${ }^{2 *}$ pred & 382.51 & 5.12 & 0.08 & 0.03 & 12.94 \\
\hline Pred mortality mortality ${ }^{2}$ pred*mortality & 382.65 & 5.26 & 0.07 & 0.03 & 13.87 \\
\hline Mortality & 382.81 & 5.42 & 0.07 & 0.03 & 15.03 \\
\hline $\begin{array}{l}\text { Pred mortality mortality }{ }^{2} \text { mortality }{ }^{3} \text { mortality* pred mortality }{ }^{2 *} \text { pred } \\
\text { mortality }{ }^{3 *} \text { pred }\end{array}$ & 384.59 & 7.20 & 0.03 & 0.01 & 36.60 \\
\hline Pred & 391.89 & 14.50 & 0.00 & 0.00 & 1408.10 \\
\hline None & 395.62 & 18.23 & 0.00 & 0.00 & 9090.63 \\
\hline Sum & - & - & 2.38 & - & - \\
\hline
\end{tabular}

Note: Weight of evidence $\left(\mathrm{w}_{\mathrm{i}}\right)$ is calculated as $\exp \left(-0.5^{*} \mathrm{AICc}\right) / \sum \exp \left(-0.5^{*} \Delta \mathrm{AICc}\right)$ and estimates the probability the model is correct. The evidence ratio (E) is calculated as $\mathrm{w}_{(\max )} / \mathrm{w}_{\mathrm{i}}$ and expresses how much more likely the best model is than the given one. Higher values indicate a less likely model. 
Table 1.4 Mixed effects generalized linear models testing survivorship in C. pipiens. Early-instar larvae were exposed to a range of mortality from harvest or predation (pred).

\begin{tabular}{|c|c|c|c|c|c|}
\hline Model Effects & $\mathrm{AICc}$ & $\begin{array}{c}\Delta \mathrm{AIC} \\
\mathrm{c}\end{array}$ & $\exp (-.5 * \Delta \mathrm{AICc})$ & $\mathrm{W}_{\mathrm{i}}$ & $\mathrm{E}$ \\
\hline Pred mortality mortality ${ }^{2}$ mortality $^{3}$ & 294.08 & 0.00 & 1.00 & 0.30 & 1.00 \\
\hline Pred mortality mortality*pred mortality ${ }^{2}$ mortality $^{3}$ & 295.68 & 1.60 & 0.45 & 0.13 & 2.23 \\
\hline pred mortality mortality* pred mortality ${ }^{2}$ & 295.85 & 1.77 & 0.41 & 0.12 & 2.42 \\
\hline $\begin{array}{l}\text { Pred mortality mortality* pred mortality }{ }^{2} \text { mortality }{ }^{2 *} \text { pred mortality } \\
\text { mortality }{ }^{3 *} \text { pred }\end{array}$ & 296.18 & 2.10 & 0.35 & 0.10 & 2.86 \\
\hline pred mortality & 296.25 & 2.17 & 0.34 & 0.10 & 2.96 \\
\hline pred mortality mortality*pred mortality ${ }^{2}$ mortality ${ }^{2 *}$ pred & 297.23 & 3.15 & 0.21 & 0.06 & 4.83 \\
\hline pred mortality mortality* pred mortality ${ }^{2}$ mortality $^{2 *}$ pred mortality ${ }^{3}$ & 297.33 & 3.25 & 0.20 & 0.06 & 5.08 \\
\hline mortality & 297.76 & 3.68 & 0.16 & 0.05 & 6.30 \\
\hline pred mortality mortality* pred mortality ${ }^{2}$ mortality $^{2 *}$ pred mortality ${ }^{3}$ & 297.78 & 3.70 & 0.16 & 0.05 & 6.36 \\
\hline mortality mortality ${ }^{2}$ mortality ${ }^{3}$ & 300.83 & 6.75 & 0.03 & 0.01 & 29.22 \\
\hline Pred & 301.64 & 7.56 & 0.02 & 0.01 & 43.82 \\
\hline None & 303.32 & 9.24 & 0.01 & 0.00 & 101.49 \\
\hline Sum & - & - & 3.34 & - & - \\
\hline
\end{tabular}

Note: Weight of evidence $\left(\mathrm{w}_{\mathrm{i}}\right)$ is calculated as $\exp \left(-0.5^{*} \mathrm{AICc}\right) / \sum \exp \left(-0.5^{*} \Delta \mathrm{AICc}\right)$ and estimates the probability the model is correct. The evidence ratio (E) is calculated as $\mathrm{w}_{(\max )} / \mathrm{w}_{\mathrm{i}}$ and expresses how much more likely the best model is than the given one. Higher values indicate a less likely model. 
Table 1.5 Mixed effects generalized linear models testing survivorship in A. triseriatus. Early-instar larvae were exposed to a range of mortality from harvest or predation (pred).

\begin{tabular}{|c|c|c|c|c|c|}
\hline Model Effects & $\mathrm{AICc}$ & $\begin{array}{c}\Delta \mathrm{AIC} \\
\mathrm{c}\end{array}$ & $\exp (-.5 * \Delta \mathrm{AICc})$ & $\mathrm{W}_{\mathrm{i}}$ & $\mathrm{E}$ \\
\hline Mortality & 420.61 & 0.00 & 1.00 & 0.54 & 1.00 \\
\hline Pred mortality & 422.48 & 1.87 & 0.39 & 0.21 & 2.55 \\
\hline Pred mortality mortality ${ }^{2}$ & 424.23 & 3.62 & 0.16 & 0.09 & 6.11 \\
\hline Pred mortality mortality*pred & 424.48 & 3.87 & 0.14 & 0.08 & 6.92 \\
\hline Pred mortality mortality ${ }^{2}$ pred* $^{*}$ mortality & 426.48 & 5.87 & 0.05 & 0.03 & 18.82 \\
\hline Pred mortality mortality ${ }^{2}$ mortality ${ }^{3}$ & 426.62 & 6.01 & 0.05 & 0.03 & 20.19 \\
\hline Pred mortality mortality ${ }^{2}$ mortality ${ }^{3}$ mortality* pred & 428.43 & 7.82 & 0.02 & 0.01 & 49.90 \\
\hline Pred mortality mortality ${ }^{2}$ mortality ${ }^{3}$ mortality* pred mortality ${ }^{2 *}$ pred & 429.34 & 8.73 & 0.01 & 0.01 & 78.65 \\
\hline $\begin{array}{l}\text { Pred mortality mortality }{ }^{2} \text { mortality }{ }^{3} \text { mortality* pred mortality }{ }^{2 *} \text { pred } \\
\text { mortality }{ }^{3 *} \text { pred }\end{array}$ & 429.97 & 9.36 & 0.01 & 0.01 & 107.77 \\
\hline None & 434.93 & 14.32 & 0.00 & 0.00 & 1286.91 \\
\hline Pred & 437.22 & 16.61 & 0.00 & 0.00 & 4044.04 \\
\hline Sum & - & - & 1.85 & - & - \\
\hline
\end{tabular}

Note: Weight of evidence $\left(\mathrm{w}_{\mathrm{i}}\right)$ is calculated as $\exp \left(-0.5^{*} \mathrm{AICc}\right) / \sum \exp \left(-0.5^{*} \Delta \mathrm{AICc}\right)$ and estimates the probability the model is correct. The evidence ratio $(\mathrm{E})$ is calculated as $\mathrm{w}_{(\max )} / \mathrm{W}_{\mathrm{i}}$ and expresses how much more likely the best model is than the given one. Higher values indicate a less likely model. 
Table 1.6 Parameter Estimates from A. Aegypti, A. Triseriatus, and C. Pipiens models.

\begin{tabular}{lccccc}
\hline \multicolumn{5}{c}{ A. aegypti } \\
\hline Effect & Estimate & Std Er & DF & t Value & Pr $>|\mathbf{t}|$ \\
Intercept & 3.7286 & 0.1168 & 4 & 31.93 & $<.0001$ \\
Pred - & -0.1502 & 0.06018 & 43 & -2.5 & $\mathbf{0 . 0 1 6 5}$ \\
Pred + & 0 &. &. &. &. \\
Mortality & -0.01939 & 0.01198 & 43 & -1.62 & 0.1128 \\
Mortality2 & 0.000873 & 0.000376 & 43 & 2.32 & $\mathbf{0 . 0 2 4 9}$ \\
Mortality3 & $-8.16 \mathrm{E}-06$ & 0 & 43 & -2.7 & $\mathbf{0 . 0 0 9 9}$ \\
\hline \multicolumn{5}{c}{ A. triseriatus } \\
\hline Intercept & 2.4634 & 0.1948 & 4 & 12.65 & $\mathbf{0 . 0 0 0 2}$ \\
Mortality & 0.01327 & 0.002984 & 50 & 4.45 & $<.0001$ \\
\hline \multicolumn{7}{c}{ C. pipiens } & & \\
\hline Intercept & 0.3699 & 0.313 & 4 & 1.18 & 0.3027 \\
Pred - & 0.8311 & 0.2416 & 43 & 3.44 & $\mathbf{0 . 0 0 1 3}$ \\
Pred + & 0 &. &. &. &. \\
Mortality & 0.114 & 0.01701 & 43 & 6.7 & $<.0001$ \\
Mortality2 & -0.00339 & 0.000239 & 43 & -14.14 & $<.0001$ \\
Mortality3 & 0.000027 & 0 & 43 & 2.15 & $\mathbf{0 . 0 3 7 4}$ \\
\hline
\end{tabular}




\section{Figure}

Figure 1.1 Observed and predicted numbers of mosquito survivors across a mortality range. Artificial mortality was applied to no predator treatments (circles) on day 2 by randomly removing $0,10,30,50$, or $70 \%$ of the initial cohort size (150) on day 2 . Predator treatments (triangles) received 1, 2, or 3 female $M$. longisetus at the start of the experiment, and the percent mortality by day 2 was determined by counting the number of surviving mosquito larvae. Predicted lines for the no predator (solid line) and predator (dashed line) treatments plot the function produced by a mixed-effects generalized linear model. Predicted values were calculated using the models with the lowest AICc's for the A. aegypti, A. triseriatus, and C. pipiens data. The predicted values for A. albopictus were calculated by using model weights to average the four models with the lowest AICc's. The effect of predator was significant for all species except $A$. triseriatus. 
a)

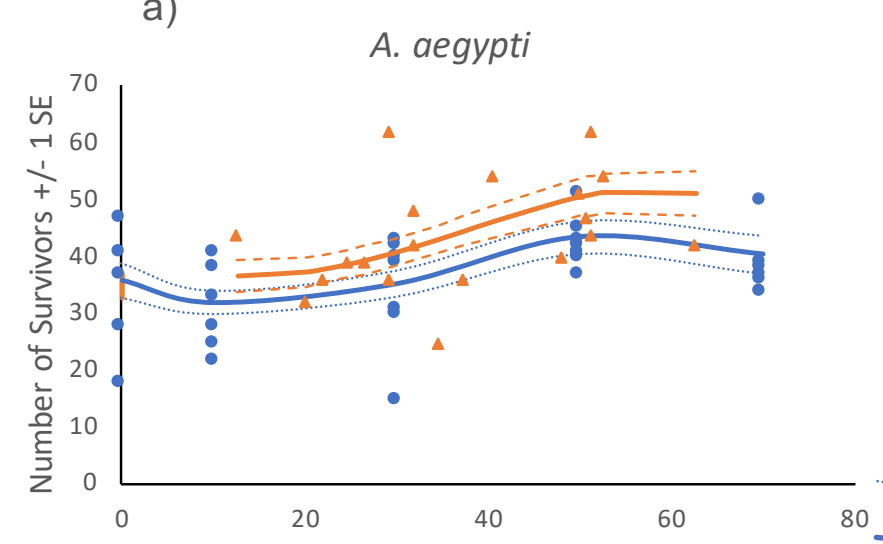

c)

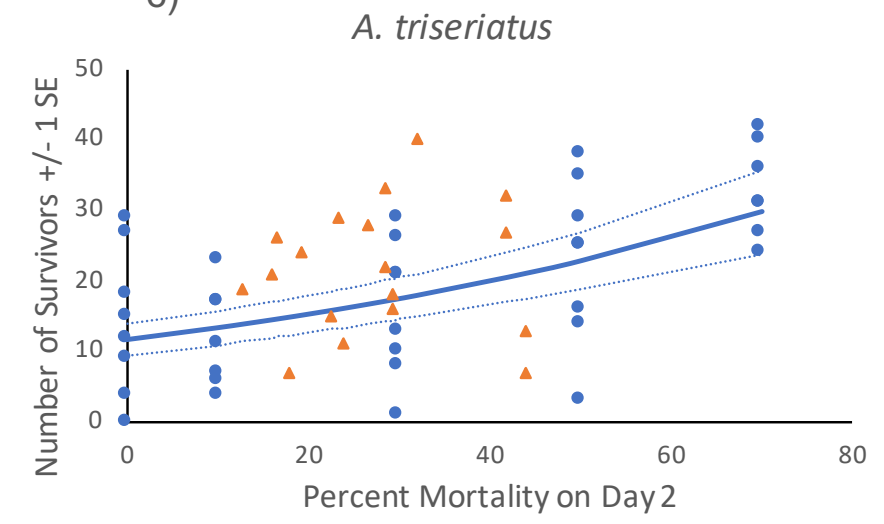

Figure 1.1 b)

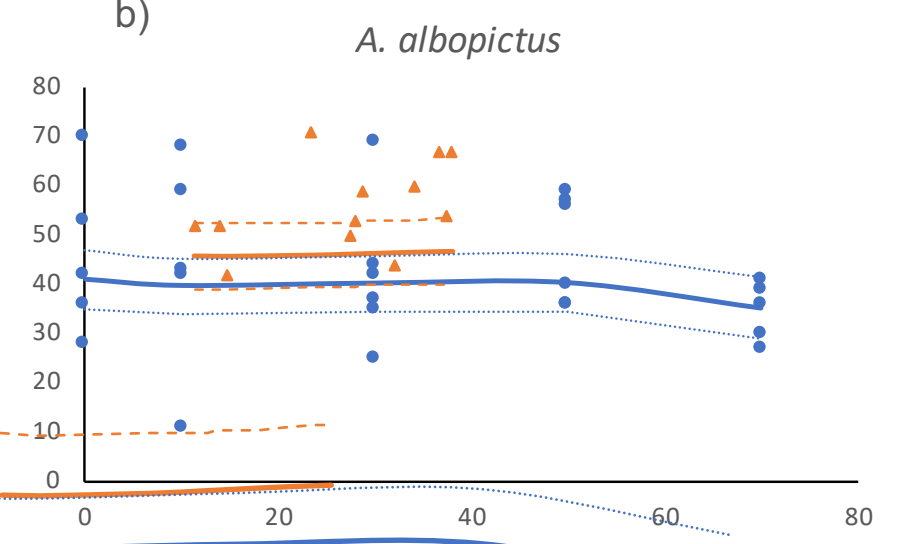

d)

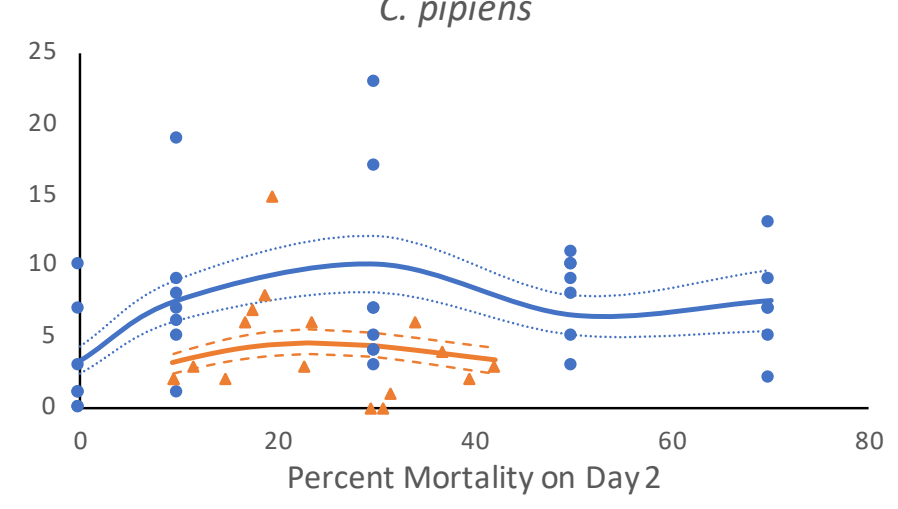

- No pred

-No pred predicted

- Pred

_Pred predicted 


\title{
CHAPTER II: THE ENEMY OF MY COMPETITOR IS MY FRIEND
}

\author{
Abstract \\ Population responses to extrinsic mortality can lead to no change in population size \\ (compensation) or an increase in population size (overcompensation) when the population is \\ negatively density dependent. This intriguing response has been the subject of various \\ theoretical studies, but few experiments have explored the how ecological context may modify \\ the phenomenon. The purpose of this study is to test the ability for three species of predators \\ alone to induce (over)compensation on a prey population and to compare predation from single \\ species to predation from a functionally diverse predator assemblage, which can lead to \\ nonlinear effects on prey populations known as emergent multiple predator effects (MPEs). \\ Larval Aedes aegypti (Diptera: Culicidae) were exposed to predation by Mesocyclops longisetus \\ (Crustacea: Copepoda), Anopheles barberi (Diptera: Culicidae), Corethrella appendiculata \\ (Diptera: Corethrellidae), or all three. The total number of survivors to adulthood, the numbers \\ of males and females, as well as a composite index of performance $r^{\prime}$ were separately analyzed in \\ ANOVAs. Predator treatment did not have a significant effect on survivorship across sexes, \\ suggesting mortality by predation was compensatory, as it did not result in a change in the \\ number of adults produced. However, the overall effect of predation on the number of female \\ survivors was significant, in contrast to the effect on males. Predator treatment had a significant \\ effect on $r^{\prime}$ with predation yielding a higher $r^{\prime}$ than the no-predator control. This suggests that, \\ while predation did not lead to significantly greater production of adults, it did release survivors \\ from sufficient levels of density-dependent effects to raise the population equilibrium, a \\ phenomenon that has been coined the 'hydra effect.' We did not find evidence for emergent \\ MPEs, as the diverse predator treatment was not significantly different from the single-species
}


treatments. This study serves as one of the first empirical examples of predation yielding the hydra effect, a phenomenon that is predicted to occur across many taxa and food webs.

Keywords: Hydra effect; MPEs, compensation, index of performance, predator-prey

\section{Introduction}

Extrinsic mortality (e.g., due to natural enemies, harvesting, or other human interventions) impinging on populations has traditionally been predicted to interact additively with intrinsic mortality sources, with greater levels of extrinsic mortality leading to reductions in population densities. However, populations regulated by negatively-density dependent effects may demonstrate counter-intuitive responses. By initially reducing the population density, extrinsic mortality may reduce detrimental density-dependent effects on the survivors. This may result in the production of the same number (compensation) or a greater number (overcompensation) of individuals surviving to the following life stage as would have been the case in the absence of extrinsic mortality. Extrinsic mortality that results in an increase in the equilibrium density of a population has been termed the 'hydra effect' (Abrams and Matsuda 2005).

Compensatory and overcompensatory responses to mortality have been demonstrated in both field and laboratory studies (Nicholson 1954, Agudelo-Silva and Spielman 1984, Washburn et al. 1991, Moe et al. 2002, Cameron and Benton 2004, Zipkin et al. 2008, Weber et al. 2016, Neale and Juliano, in review). Numerous theoretical studies have attempted to elucidate the mechanisms under which the phenomenon occurs (reviewed in Abrams 2009). The timing of extrinsic mortality relative to the onset of density-dependent effects is predicted to influence the likelihood of overcompensation, with mortality occurring prior to density-dependence postulated to lead to overcompensation and increased population sizes (Jonzen and Lundberg 1999, Abrams 
2009, Pardini et al. 2009). This hypothesis, known as the 'temporal separation of mortality and density dependence hypothesis', was recently supported in an empirical study on container mosquitoes (McIntire and Juliano 2018). Furthermore, the extrinsic mortality rate (i.e., proportion killed) is expected to have an effect on whether additive, compensatory, or overcompensatory effects are observed (Sandercock et al. 2011, Neale and Juliano, in review) and these effects appear to be related to competitive abilities of the species involved (Neale and Juliano, in review). We have found only a few published studies empirically examining the mechanisms of the hydra effect (Sandercock et al. 2011, McIntire and Juliano 2018), and more empirical studies are needed to determine the conditions under which it occurs.

Predation is a common source of extrinsic mortality for animal populations in the wild, and mathematical models predict that predation can lead to the hydra effect in prey populations (Cortez and Abrams 2016). However, only two of the aforementioned empirical examples included predation as a mortality source, both in container mosquito systems (Nannini and Juliano 1998, Neale and Juliano, in review). In natural food webs, many prey populations face predation from multiple predators (Sih et al. 1998). Understanding how predation by multiple predator species differs from a single predator species in hydra effect studies is critical to predicting the occurrence of the phenomenon in nature. However, we have found no published studies examining the effects of multiple predators on overcompensation and the hydra effect. Increasing predator functional or phylogenetic diversity can result in emergent multiple predator effects (MPE's), which are characterized by nonlinear effects (i.e., risk reduction or risk enhancement) on prey populations, which often result in an increase or decrease in predation rates relative to that observed with single predators (Sih et al. 1998, Schmitz 2007, Bruno and Cardinale 2008, Greenop et al. 2018). A recent meta-analysis of studies on terrestrial arthropod 
systems found predator functional diversity was more important in determining the outcome on prey than phylogenetic diversity (Greenop et al. 2018). The degree of overlap in foraging domains and hunting modes between the different predator functional groups is predicted to determine if emergent MPE's will occur and whether they will be risk enhancing or reducing, as foraging domain and hunting mode determine the likelihood of intraguild predation and availability of prey refugia (Schmitz 2007). Since the level of extrinsic mortality influences the likelihood of overcompensatory responses, emergent MPE's may result in levels of overcompensation (including absence of overcompensation) that deviate from responses to single predator species.

The purpose of this study is to test the ability of predators to induce compensation or overcompensation in a prey species. We hypothesize that predation from a single species occurring early in the development of a density-dependent prey population leads to overcompensatory mortality, and predation from multiple predator species leads to either increased or decreased strength of overcompensation due to emergent MPEs that alter mortality rates.

We tested our hypotheses using Aedes aegypti (Diptera: Culicidae) as the prey species. The complex life-cycle and negatively density dependent survival of the larval stage (Dye 1984) are consistent with the assumptions of the models of populations developed by Abrams (2009). Overcompensation has been demonstrated in this species (Neale and Juliano, in review) as well as its congeners, A. sierrensis (Washburn et al. 1991), A. albopictus (McIntire and Juliano 2018), and $A$. triseriatus (Neale and Juliano, in review). The predators we included were Mesocyclops longisetus (Crustacea: Copepoda), Anopheles barberi (Diptera: Culicidae), and Corethrella appendiculata (Diptera: Corethrellidae). All three predators have been demonstrated to be 
efficient predators of Aedes larvae under similar conditions (Marten et al. 1994, Nannini and Juliano 1998, Alto et al. 2009). They are size-selective, feeding primarily on early instar larvae (Nannini and Juliano 1998, Soumare et al. 2004, Alto et al. 2009). This size-selectivity is ideal for inducing overcompensation, as it concentrates the mortality early in prey development and potentially separates mortality due to predation temporally from the density-dependent effects, which are expected to increase as immatures grow. The three predators differ in hunting domains. Mesocyclops longisetus swims throughout the water column, lunging at prey when it passes within $\sim 1 \mathrm{~mm}$ (Marten and Reid 2007). Anopheles barberi sits in the surface tension and ambushes larvae as they surface (Clements 1992). Corethrella appendiculata primarily sits at the bottom of the water column and preys on mosquito larvae when they browse in the substrate (Kesavaraju et al. 2007).

\section{Material and Methods}

\section{Organism Collection}

Aedes aegypti used in this study were from a laboratory colony originating from pupae and larvae field-collected from Vero Beach, FL approximately 1 year before the start of this experiment. To maintain the colony, larvae were reared in plastic pans at $25^{\circ} \mathrm{C}$ and provided bovine liver powder. Adults were given a constant supply of $20 \%$ sucrose solution, and blood meals were provided from anesthetized guinea pigs (IUCAC\# 842043).

Mesocyclops longisetus were from a laboratory colony maintained at Illinois State University in Normal, IL, which originated from a colony maintained at the Florida Medical Entomology Laboratory (FMEL) in Vero Beach, FL. Corethrella appendiculata were $4^{\text {th }}$ instars field collected from tree holes on the FMEL grounds. Larvae were housed in water from the tree holes at $25^{\circ} \mathrm{C}$ until the start of the experiment. Anopheles barberi were collected as larvae in 
rain-filled buckets at Parklands Merwin Nature Preserve near Lexington, IL. To maximize the number of late-instar larvae available at the start of the experiment, $3^{\text {rd }}$ and $4^{\text {th }}$ instars were housed at $22^{\circ} \mathrm{C}$ to delay pupation, while $1^{\text {st }}$ and $2^{\text {nd }}$ instars were housed at $25^{\circ} \mathrm{C}$.

\section{Experimental Setup}

Four days prior to the beginning of the experiment, $500 \mathrm{ml}$ plastic containers were filled with $400 \mathrm{ml}$ ultrapure water, $1 \mathrm{~g}$ dried live oak (Quercus virginiana) leaves collected from Vero Beach, FL, $0.05 \mathrm{~g}$ dried decorated crickets (Gryllodes sigillatus) from a colony maintained at Illinois State University, and $100 \mu 1$ microbial inoculum, from rain-filled buckets in Merwin Nature Preserve, Lexington, IL. Lids were placed on the containers with holes punched for ventilation. The containers were housed in an environmental chamber at $25^{\circ} \mathrm{C}$ until the beginning of the experiment to allow the establishment of a microbial community to serve as food resources for mosquito larvae.

Aedes aegypti eggs were hatched 24 hours prior to the start of the experiment by placing strips of egg papers in 4 dram glass vials containing $0.4 \mathrm{~g} / 1$ Difco $^{\mathrm{TM}}$ nutrient broth (Becton, Dickinson and Company, Sparks, MD) at $25^{\circ} \mathrm{C}$. At the start of the experiment, hatchling larvae were rinsed in ultrapure water and 150 were placed in each experimental container $(n=15)$.

Containers were randomly assigned one of five predator treatments: no predator, M. longisetus, C. appendiculata, A. barberi, and diverse. The single-species treatments received three predator individuals, whereas the diverse treatment received one individual of each predator species.

Only non-gravid adult female M. longisetus, $4^{\text {th }}$ instar $C$. appendiculata, and $3^{\text {rd }}$ and $4^{\text {th }}$ instar $A$. barberi were used. Multiple $A$. barberi instars were included because of a limited number of larvae available. Since 4th instars consume greater numbers of Aedes prey than $3^{\text {rd }}$ instars (Nannini and Juliano 1998), the $A$. barberi treatment received one $4^{\text {th }}$ and two $3^{\text {rd }}$ instars, and 
diverse containers each received a $4^{\text {th }}$ instar. Once prey and predators were added to each container, they were placed in an environmental chamber set to $25^{\circ} \mathrm{C}$ and a $14: 10$ light:dark photoperiod.

Containers were checked daily for A. aegypti pupae and survival of predators. A. aegypti pupae were removed, placed in 0.25 dram vials with cotton stoppers, and returned to the environmental chamber, and any dead or missing predators were replaced. All predators were removed on day 6 because the replacement stock of $A$. barberi larvae was depleted. Due to the size selectivity of the three predators and the developmental stage of prey by day 6 , only minimal amounts of predation would have occurred if the predators remained. On days 16 and $300.5 \mathrm{~g}$ dried live oak leaves and $0.025 \mathrm{~g}$ dried decorated crickets were added to replenish resources for bacteria and fungi that are the food of $A$. aegypti.

Pupae were checked daily for eclosion. Water was removed from vials containing adults and the vial was placed in a drying oven at $70^{\circ} \mathrm{C}$ for $>48$ hours. All individuals reaching adulthood were counted as survivors. Female wings were dissected and photographed with a digital camera, and wing lengths were measured in Image J 1.51.

\section{Index of Performance}

Using data collected on female survivorship to adulthood, development time to adulthood, and predicted fecundity based on body size, Livdahl and Sugihara's (1984) index of performance $r^{\prime}$ was calculated for each container (Equation 1). This index synthesizes information on these variables in a manner analogous to calculations of net reproductive rate $\left(\mathrm{R}_{0}\right)$ and cohort generation time $\left(\mathrm{T}_{\mathrm{c}}\right)$ from a cohort life table. This index of performance provides an estimate of cohort rate of change and was used to assess how predator treatments affected population growth for experimental cohorts in each container. We infer that cohorts of 150 
larvae receiving a particular predator treatment are farther below equilibrium density if their index of performance is farther above 0 .

Equation 1 Livdahl and Sugihara's (1984) index of performance

$$
r^{\prime}=\left[\frac{\ln \left[\left(1 / N_{0}\right) \sum_{x} A_{x} f\left(w_{x}\right)\right]}{D+\left[\sum_{x} x A_{x} f\left(w_{x}\right) / \sum_{x} A_{x} f\left(w_{x}\right)\right]}\right]
$$

$N_{0}$ is the initial number of females (assumed to be $50 \%$ of the initial 150 larvae), $A_{x}$ is the number of new females emerging on day $x, w_{x}$ is the mean wing length of new females emerging on day $x$, and $D$ is the estimated days between female eclosion and oviposition, (estimated to be 12 days; Grill and Juliano 1996). Production of female offspring $f\left(w_{x}\right)$ was estimated as a function of wing length using the regression provided by Briegel (1990): $f\left(w_{x}\right)=0.5\left(2.5 w_{x}{ }^{3}-\right.$ 8.616).

Statistical Analysis

One-factor ANOVA's were used to analyze the effects of predator treatment on overall survivorship, female survivorship, male survivorship, $r^{\prime}$, female size, and female development time using PROC GLM in SAS 9.4. Contrast statements were used as a post hoc tests for the analyses of index of performance, female survivorship, and female development time, and sequential Bonferroni methods were used to correct for multiple comparisons (Holm 1979). The contrasts we tested were predator versus no predator, single-predator versus diverse, and pairwise comparisons of each of the three single-predator treatments. 


\section{Results}

The no predator treatment produced the lowest number of survivors across both sexes, but the overall treatment effect was not significant $\left(\mathrm{F}_{4,14}=2.82, \mathrm{p}=0.0838\right.$, Figure 2.1). The effect of predator on the number of adult males produced was not significant $\left(\mathrm{F}_{4,14}=0.72, \mathrm{p}=0.5994\right)$, but the effect on the number female adults produced was significant $\left(\mathrm{F}_{4,14}=4.03, \mathrm{p}=0.0337\right)$. However, none of the post hoc contrasts produced significant differences after correcting for multiple tests (Table 2.1, Figure 2.1).

The overall ANOVA on $r^{\prime}$ values indicated a significant effect of predator treatment $\left(\mathrm{F}_{4,14}=4.24, \mathrm{p}=0.029\right)$. No predator treatments produced the lowest value of $r^{\prime}$ at 0.0107 , whereas C. appendiculata produced the largest $r^{\prime}$ at 0.0438 (Figure 2.2). Post hoc analyses indicated predation led to an increase in $r^{\prime}$ compared to no predation (Table 2.1, Figure 2.2). Predation by a single predator treatment was not significantly different from the diverse treatment, and there were no significant pairwise comparisons among the three single-predator treatments (Table 2.1).

Predation from M. longisetus produced the largest average female wing length, but the overall treatment effect was not significant $\left(\mathrm{F}_{4,14=} 2.17, \mathrm{p}=0.1457\right.$, Figure $\left.2.3 \mathrm{a}\right)$. The predator treatment had a significant effect on the average number of days to adulthood for females $\left(\mathrm{F}_{4,14}=3.56, \mathrm{p}=0.0469\right)$, with the average time to adulthood in predator treatments significantly lower than that in control (Table 2.1, Figure 2.3b).

\section{Discussion}

The absence of a significant differences in adult production among the predator treatments and the control indicates mortality from predation induced compensation in the $A$. aegypti cohorts. We did not observe significant overcompensatory mortality in any treatment, and the adult production in the diverse predator treatment was not significantly different from 
any single-species predator treatment; therefore, our results do not support our hypothesis. The compensatory response suggests predation removed individuals that would have otherwise died from density-dependent effects, but this removal did not release the surviving population from a sufficient level of these density-dependent effects to increase significantly production of adults.

Predation led to a significantly larger index of performance $\left(r^{\top}\right)$, suggesting that predation had the counter-intuitive effect of increasing equilibrium compared to the no-predator treatment (Livdahl and Sugihara 1984). The overall F test on female survivorship was significant, and female adult production trended to be greater with predation, but this contrast was marginally non-significant. This may be explained by insufficient power to detect differences due to the small sample size. The differential effects of predation on male versus female survivorship is consistent with contrasts in resource requirements between the two sexes. Females require more time to reach adulthood and emerge as larger adults, indicating they have larger resource demands than males (Wormington and Juliano 2014a, 2014b). Females would thus receive a greater benefit to conspecific mortality, as they are the most resource limited.

All three components of the index of performance - survivorship, development time, and fecundity - displayed trends consistent with the differences in $r^{\prime}$. Predation led to higher mean number of survivors, higher mean fecundity, and lower mean development time. However, since the effect of predation on female development time was the only one that led to significant differences in post hoc comparisons between predator versus no predator, the greater population equilibrium density in response to extrinsic mortality was primarily mediated by females reaching adulthood faster in the presence of predation. The faster development of females was likely caused by the weakening of density-dependent effects by reductions in population density. The difference in $r^{\prime}$ suggests that equilibrium population densities would be greater when 
exposed to predation compared to no predator if the experimental populations were allowed to persist for multiple generations.

Overcompensation has been induced in A. aegypti by predation from M. longisetus (Neale and Juliano, in review). However, the present study failed to produce the same result. The relatively small sample size may limit our power to detect differences among treatments despite the tendency for predator treatments to produce more adults, particularly more females (Figure 2.1). Furthermore, the A. aegypti population tested in the past study originated in New Orleans, LA, while the population tested in this study originated from Vero Beach, FL. Population-level differences in intraspecific competitive abilities and responses to predation may have influenced the contrasting results in the two experiments, as well as differences in exposure to predation in the two experiments. The compensatory response to $A$. barberi predation is consistent with Nannini and Juliano (1998), in which predation by $A$. barberi induced compensation in A. triseriatus, a congener to the A. aegypti tested in this study. However, comparisons of (over)compensatory responses between species should be made with caution, as differences in responses to population density and competitive abilities can lead to interspecific variation in the level and likelihood of (over)compensation (Neale and Juliano, in review).

The single-species predator treatments produced the same response as the diverse predator treatment; therefore, we did not find evidence for emergent MPE's. Our results indicate the effects of the three predators were substitutable. Predator substitutability is predicted to occur when the predators exhibit non-overlapping habitat domains and prey exhibit broad habitat domains (Schmitz 2007). However, this prediction may be complicated when prey demonstrate predator-specific avoidance behaviors, which may result in risk enhancement by predator facilitation. In our experiment, habitat domains for A. barberi and C. appendiculata have little 
or no overlap, but the domains of each overlap with the uppermost (A. barberi) and lowermost (C. appendiculata) portions of the domain for M. longisetus, which hunts throughout the entire water column (Clements 1992, Kesavaraju et al. 2007, Marten and Reid 2007). Scenarios in which the habitat domains of multiple predators overlap are predicted to lead to emergent MPE's, the nature of which depend on the respective hunting modes of the predators and the degree of overlap with prey habitat domain (Schmitz 2007). However, since the degree of overlap between $M$. longisetus and either of the other two predators is small, the chances for interactions between predators may have been minimal. We found no evidence of intraguild predation, one mechanism which can lead to risk reduction when predator habitat domains overlap (Schmitz 2007). Habitats with shorter water columns would compress the habitat domain of M. longisetus and increase the proportion of overlap with C. appendiculata and A. barberi, thus increasing the likelihood of predator interactions and emergent MPEs.

We have demonstrated predation on larval $A$. aegypti by three predator species, alone and in polyculture, can induce compensation in the production of adults. Our evidence suggests predation may relieve A. aegypti populations of a sufficient level of density-dependent effects to increase population equilibrium and induce the hydra effect. Since this effect is predicted to occur in a variety of food web structures, these results provide insight on a phenomenon that affects many taxa (Cortez and Abrams 2016). Further work should be conducted to elucidate the mechanisms mediating (over)compensation and the hydra effect to better predict their occurrence in nature, allowing more effective pest management, conservation, and harvest strategies (Abrams 2002, Ratikainen et al. 2008, Zipkin et al. 2009, Sandercock et al. 2011). 


\section{References}

Abrams, P. A. 2002. Will small population sizes warn us of impending extinctions? - Am. Nat. 160: 293-305.

Abrams, P. A. 2009. When does greater mortality increase population size? The long history and diverse mechanisms underlying the hydra effect. - Ecol. Lett. 12: 462-474.

Abrams, P. A. and Matsuda, H. 2005. The effect of adaptive change in the prey on the dynamics of an exploited predator population. - Can. J. Fish. Aquat. Sci. 62: 758-766.

Agudelo-Silva, F. and Spielman, A. 1984. Paradoxical effects of simulated larviciding on production of adult mosquitoes. - Am. J. Trop. Med. Hyg. 33: 1267-1269.

Alto, B. W. et al. 2009. Stage-dependent predation on competitors: consequences for the outcome of a mosquito invasion. - J. Anim. Ecol. 78: 928-936.

Briegel, H. 1990. Metabolic relationship between female body size, reserves, and fecundity of Aedes aegypti. - J. Insect Physiol. 36: 165-172.

Bruno, J. F. and Cardinale, B. J. 2008. Cascading effects of predator richness. - Front. Ecol. Environ. 6: 539-546.

Cameron, T. C. and Benton, T. G. 2004. Stage-structured harvesting and its effects: an empirical investigation using soil mites. - J. Anim. Ecol. 73: 996-1006.

Clements, A. N. 1992. The biology of mosquitoes, vol. I, development, nutrition, and reproduction. - Chapman and Hall.

Cortez, M. H. and Abrams, P. A. 2016. Hydra effects in stable communities and their implications for system dynamics. - Ecology 97: 1135-1145.

Dye, C. 1984. Models for the population dynamics of the yellow fever mosquito, Aedes aegypti. - J. Anim. Ecol. 53: 247-268. 
Greenop, A. et al. 2018. Functional diversity positively affects prey suppression by invertebrate predators: a meta-analysis. - Ecology in press.

Grill, C. P. and Juliano, S. A. 1996. Predicting species interactions based on behaviour: predation and competition in container-dwelling mosquitoes. - J. Anim. Ecol. 65: 63-76.

Holm, S. 1979. A simple sequentially rejective multiple test procedure. - Scand. J. Stat. 6: 65-70.

Jonzen, N. and Lundberg, P. 1999. Temporally structured density-dependence and population management. - Ann. Zool. Fennici 36: 39-44.

Kesavaraju, B. et al. 2007. Behavioural responses of larval container mosquitoes to a sizeselective predator. - Ecol. Entomol. 32: 262-272.

Livdahl, T. P. and Sugihara, G. 1984. Non-linear interactions of populations and the importance of estimating per capita rates of change. - J. Anim. Ecol. 53: 573-580.

Marten, G. G. and Reid, J. W. 2007. Cyclopoid copepods. - J. Am. Mosq. Control Assoc. 23: 6592.

Marten, G. G. et al. 1994. Use of cyclopoid copepods for mosquito control. - Hydrobiologia 292-293: 491-496.

McIntire, K. M. and Juliano, S. A. 2018. How can mortality increase population size? A test of two mechanistic hypotheses. - Ecology in press.

Moe, S. J. et al. 2002. Density-dependent compensation in blowfly populations give indirectly positive effects of a toxicant. - Ecology 83: 1597-1603.

Nannini, M. and Juliano, S. A. 1998. Effects of the facultative predator Anopheles barberi on population performance of its prey Aedes triseriatus (Diptera: Culicidae). - Ann. Entomol. Soc. Am. 1: 33-42. 
Neale, J. T. and Juliano, S. A. 2018. When does less equal more? Assessing the mechanisms driving compensatory mortality and the hydra effect.

Nicholson, A. J. 1954. An outline of the dynamics of animal populations. - Aust. J. Zool. 2: 965.

Pardini, E. A. et al. 2009. Complex population dynamics and control of the invasive biennial Alliaria petiolata (garlic mustard). - Ecol. Appl. 19: 387-397.

Ratikainen, I. I. et al. 2008. When density dependence is not instantaneous: theoretical developments and management implications. - Ecol. Lett. 11: 184-198.

Sandercock, B. K. et al. 2011. Is hunting mortality additive or compensatory to natural mortality? Effects of experimental harvest on the survival and cause-specific mortality of willow ptarmigan. - J. Anim. Ecol. 80: 244-258.

Schmitz, O. J. 2007. Predator diversity and trophic interactions. - Ecology 88: 2415-2426.

Sih, A. et al. 1998. Emergent impacts of multiple predators on prey. - Trends Ecol. Evol. 13: 350-355.

Soumare, M. K. et al. 2004. Prey and size preference of Mesocyclops longisetus (Copepoda) for Aedes albopictus and Culex quinquefasciatus larvae. - J Am Mosq Control Assoc 20: 305310.

Washburn, J. O. et al. 1991. Regulatory role of parasites: impact on host population shifts with resource availability. - Science (80-. ). 253: 185-188.

Weber, M. J. et al. 2016. Compensatory response of invasive common carp Cyprinus carpio to harvest. - Fish. Res. 179: 168-178.

Wormington, J. D. and Juliano, S. A. 2014a. Sexually dimorphic body size and development time plasticity in Aedes mosquitoes (Diptera: Culicidae). - Evol. Ecol. Res. 16: 223-234. 
Wormington, J. D. and Juliano, S. A. 2014b. Hunger-dependent and sex-specific antipredator behaviour of larvae of a size-dimorphic mosquito. - Ecol. Entomol. 39: 548-555.

Zipkin, E. F. et al. 2008. Overcompensatory response of a smallmouth bass (Micropterus dolomieu) population to harvest: release from competition? - Can. J. Fish. Aquat. Sci. 65: $2279-2292$.

Zipkin, E. F. et al. 2009. When can efforts to control nuisance and invasive species backfire? Ecol. Appl. 19: 1585-1595. 


\section{Table}

Table 2.1 Post hoc tests comparing treatment effects on $r^{\prime}$, female adult production, and female development time. Contrast statements compared effects predator versus no predator, single predator versus diverse, and pairwise comparisons of individual species treatments on $A$. aegypti index of performance, number of female adults produced, and female days to adulthood. Bold $\mathrm{p}$ values indicate significant comparisons after correcting for multiple comparison. 
Table 2.1

\begin{tabular}{|c|c|c|c|}
\hline \multicolumn{4}{|c|}{ Index of performance $\left(r^{\prime}\right)$} \\
\hline Contrast & $\mathrm{DF}$ & F Value & $\operatorname{Pr}>F$ \\
\hline Predator vs no predator & 1 & 12.1 & 0.0059 \\
\hline Single predator vs diverse & 1 & 0.06 & 0.8123 \\
\hline A. barberi vs C. appendiculata & 1 & 4.81 & 0.053 \\
\hline M. longisetus vs $C$. appendiculata & 1 & 1.4 & 0.2635 \\
\hline A. barberi vs $M$. longisetus & 1 & 1.02 & 0.3371 \\
\hline \multicolumn{4}{|c|}{ Number of female adults } \\
\hline Predator vs no predator & 1 & 7.78 & 0.0192 \\
\hline Single predator vs diverse & 1 & 0.01 & 0.9153 \\
\hline A. barberi vs $C$. appendiculata & 1 & 7.14 & 0.0234 \\
\hline M. longisetus vs $C$. appendiculata & 1 & 5.16 & 0.0464 \\
\hline A. barberi vs $M$. longisetus & 1 & 0.16 & 0.6969 \\
\hline
\end{tabular}

Female days to adulthood

\begin{tabular}{llcc}
\hline Predator vs no predator & 1 & 11.71 & $\mathbf{0 . 0 0 6 5}$ \\
Single predator vs diverse & 1 & 1.97 & 0.1902 \\
A. barberi vs C. appendiculata & 1 & 0.55 & 0.4736 \\
M. longisetus vs C. appendiculata & 1 & 0.07 & 0.7987 \\
A. barberi vs $M$. longisetus & 1 & 0.23 & 0.6396
\end{tabular}




\section{Figures}

Figure 2.1 Mean numbers of adult $A$. aegypti produced by predator treatment. Larvae were exposed to no predators, 3 A. barberi, 3 M. longisetus, 3 C. appendiculata, or 1 of each predator species.

Figure 2.2 Mean indices of performance $\left(r^{\top}\right)$ by predator treatment. Cohorts of larvae were reared in the presence of no predators, 3 A. barberi, 3 M. longisetus, 3 C. appendiculata, or 1 of each predator species. Brackets indicate the significant difference between predator vs. no predator.

Figure 2.3 Mean female wing length (a) and days to adulthood (b) by predator treatment. Larval A. aegypti were reared in the presence of no predators, 3 A. barberi, 3 M. longisetus, $3 C$. appendiculata, or 1 of each predator species. Brackets indicate the difference between predator vs. no predator. 


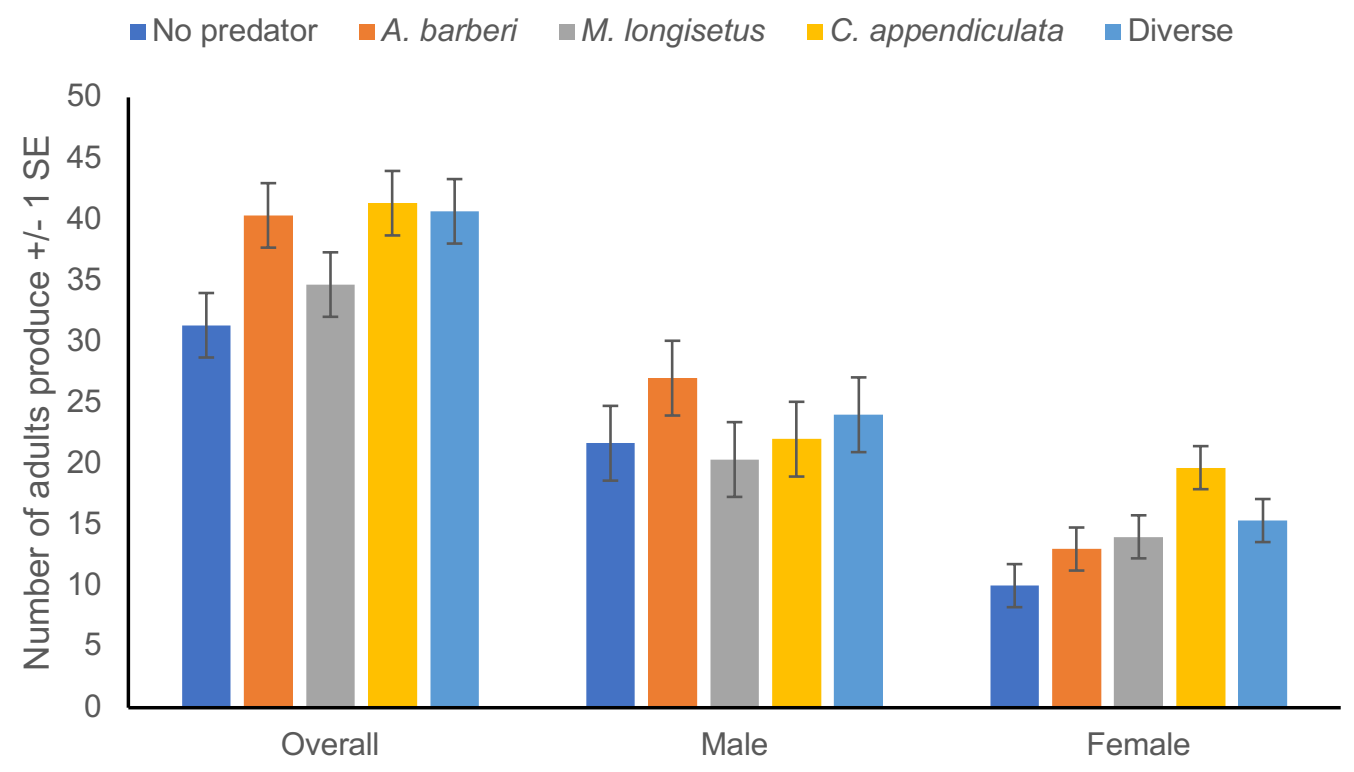

Figure 2.1 


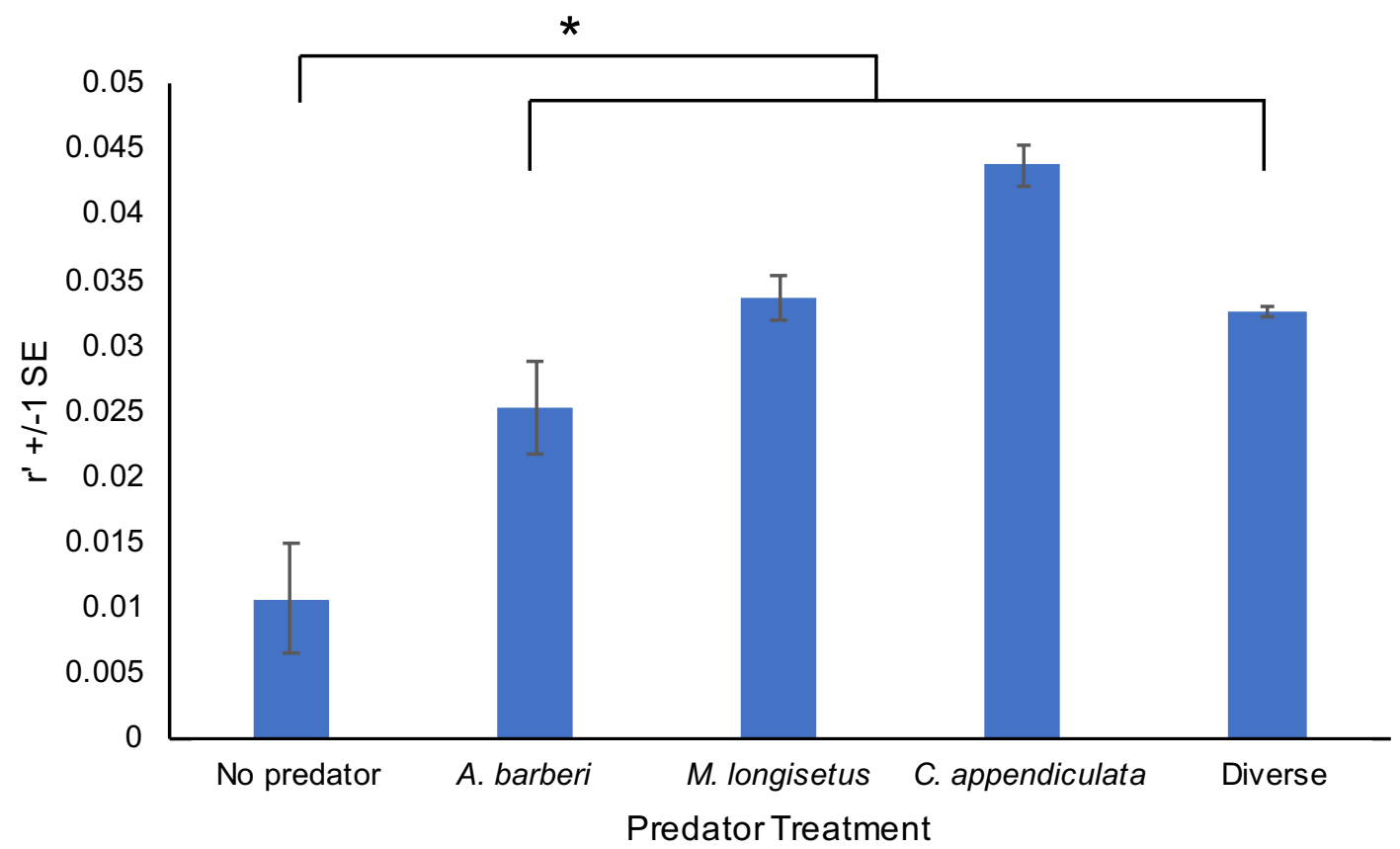

Figure 2.2 

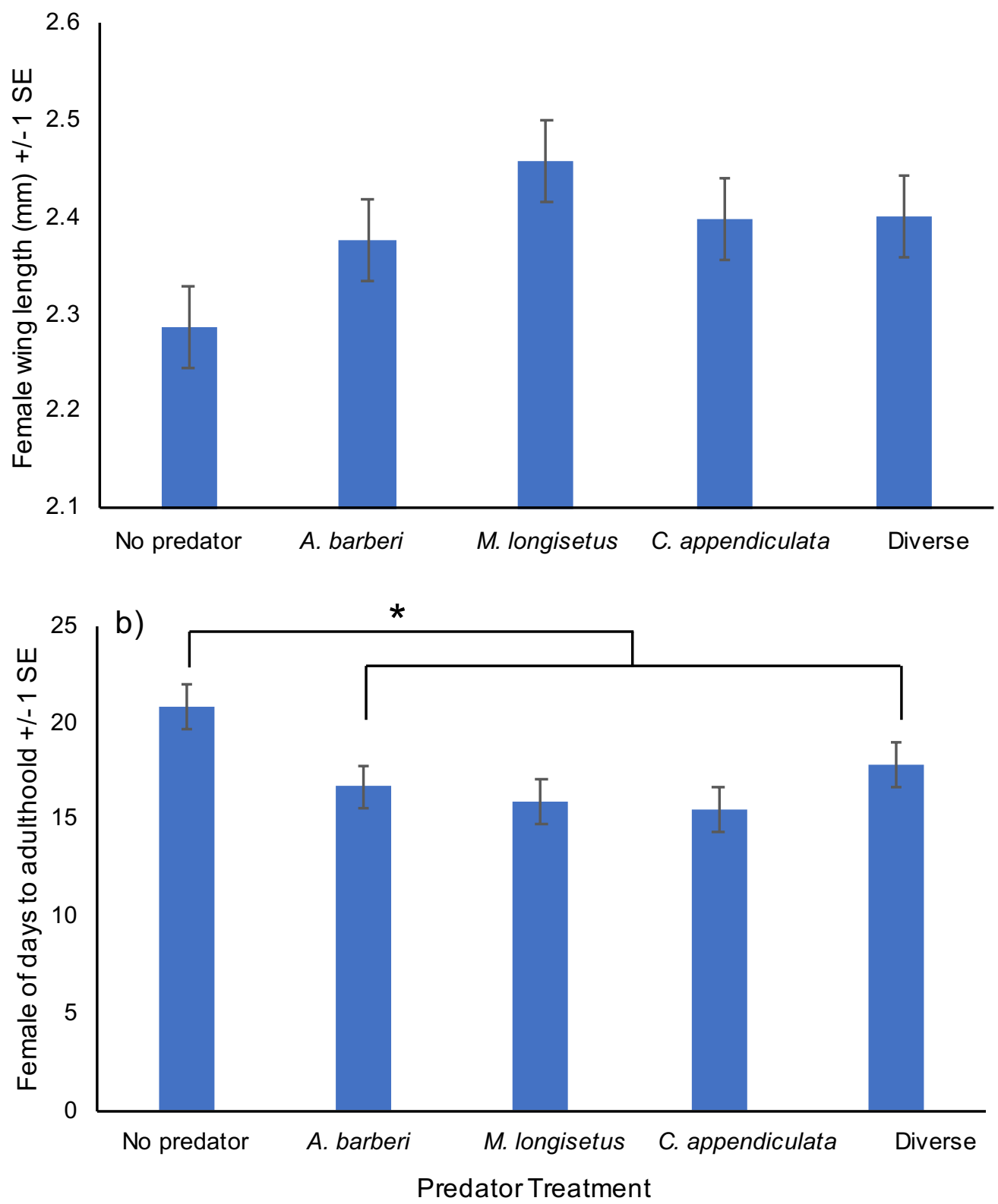

Figure 2.3 